7hts

Printed January 1983

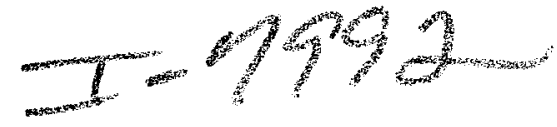

\title{
DRAC A User-Friendly \\ Computer Code for Modeling \\ Transient Thermohydraulic \\ Phenomena in Solar-Receiver \\ Tubing
}

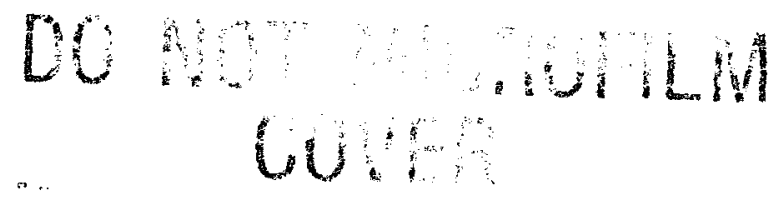

W. S. Winters

Prepared by

Sandia National Laboratories

Albuquerque, New Mexico 87185 and Livermore, California 94550

for the United States Department of Energy

under Contract DE-AC04-76DP00789 


\section{DISCLAIMER}

This report was prepared as an account of work sponsored by an agency of the United States Government. Neither the United States Government nor any agency Thereof, nor any of their employees, makes any warranty, express or implied, or assumes any legal liability or responsibility for the accuracy, completeness, or usefulness of any information, apparatus, product, or process disclosed, or represents that its use would not infringe privately owned rights. Reference herein to any specific commercial product, process, or service by trade name, trademark, manufacturer, or otherwise does not necessarily constitute or imply its endorsement, recommendation, or favoring by the United States Government or any agency thereof. The views and opinions of authors expressed herein do not necessarily state or reflect those of the United States Government or any agency thereof. 


\section{DISCLAIMER}

Portions of this document may be illegible in electronic image products. Images are produced from the best available original document. 
7

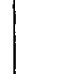

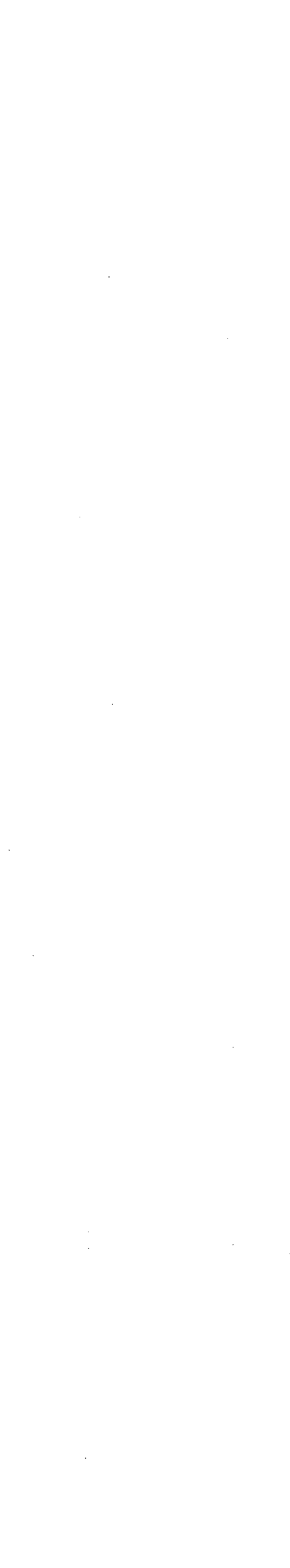


SAND82-8744

Unlimited Distribution $-4 C-62$

Printed January 1983

DRAC: A User-Friendly Computer Code for Modeling Transient

Thermohydraulic Phenomena in Solar-Receiver Tubing

\author{
W. S. Winters \\ Thermal Sciences Division \\ Sandia National Laboratories, Livermore
}

\begin{abstract}
This document is intended to familiarize potential users with the capabilities of DRAC (Dynamic Receiver Analysis Code). DRAC is the first in a series of "user friendly" driver programs for the more general code, TOPAZ (Transient-One-

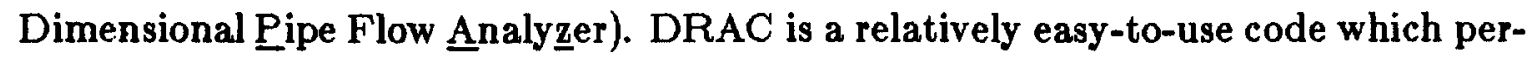
mits the user to model both transient and steady-state thermohydraulic phenomena in solar receiver tubing. Users may specify arbitrary, time-dependent, incident heat flux profiles and/or flow rate changes and DRAC will calculate the resulting transient excursions in tube wall temperature and fluid properties. Radiative and convective losses are accounted for and the user may model any receiver fluid (compressible or incompressible) for which thermodynamic data exists. A description of the DRAC code, a comprehensive set of steady-state validation calculations, and detailed user instructions are presented in this report.
\end{abstract}

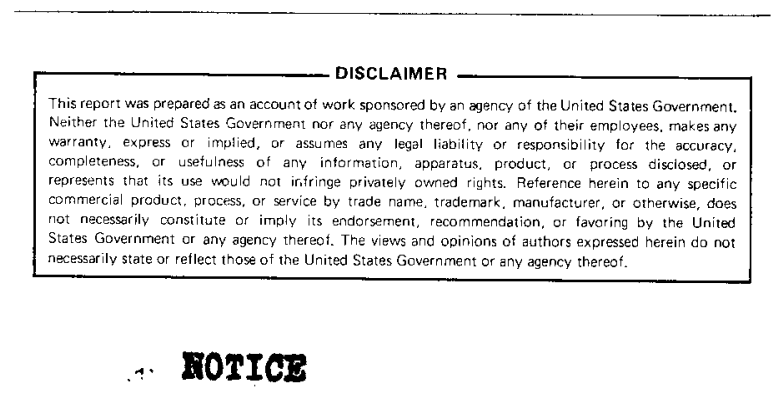

PORTIONS OF THIS REPORT ARE THTEGIBLS. It has been reproduced from tho best avallablo copy to permit the broadest possible aval1ability.

OSTTHBUTTON OF THIS DOCUMENT IS UNLIMITEO 

II. DRAC Description $\quad 15$

$\begin{array}{ll}\text { A. The DRAC Problem } & 15\end{array}$

$\begin{array}{ll}\text { B. Mesh Generation } & 17\end{array}$

III. DRAC Steady-State Validation Calculations 23

IV. DRAC User Instructions 39

A. Requirements for Input 39

$\begin{array}{ll}\text { B. Sample Problem } & 41\end{array}$

V. Conclusions/Future Activities $\quad 46$

$\begin{array}{ll}\text { VI. References } & 47\end{array}$

APPENDICES

A. DRAC Printout of Header Information 49

B. DRAC Abbreviated Printout of Mesh Generation Table 51

C. DRAC Abbreviated Printout of Major and Minor Edits 53 


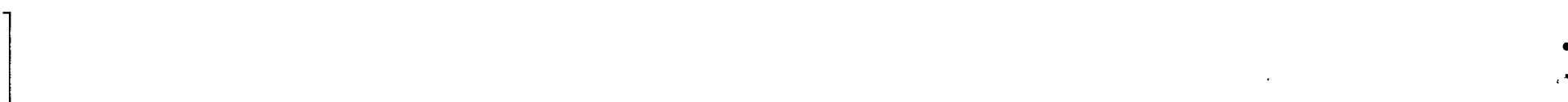


Figure 2. Schematic of the DRAC Model

Figure 3. Spatial Nodalization of the Fluid Stream

Figure 4. Spatial Nodalization of the Tube Wall

Figure 5. Nodal Numbering for $N_{c v}=N_{R}=N_{c}=3$

Figure 6. Normalized Axial Crown Incident Heat Flux Distribution

Figure 7. Comparison of DRAC and THRMHYD Steady-State Axial Fluid and Outer Crown Temperature Distributions: Sodium Test Case

Figure 8. Comparison of DRAC and THRMHYD Steady-State Axial Pressure Distributions: Sodium Test Case

Figure 9. Comparison of DRAC and THRMHYD Steady-State Radial $\left(\theta_{A}=0^{\circ}\right)$ Tube Wall Temperature Distribution: Sodium Test Case

Figure 10. Comparison of DRAC and THRMHYD Steady-State Distribution: Sodium Test Case

Figure 11. Comparison of DRAC and THRMHYD Steady-State Axial Fluid and Outer Crown Temperature Distributions: Molten Salt Test Case

Figure 12. Comparison of DRAC and THRMHYD Steady-State Axial Pressure Distributions: Molten Salt Test Case 
Figure 13. Comparison of DRAC and THRMHYD Steady-State

Radial $\left(\theta_{A}=0^{\circ}\right)$ Tube Wall Temperature Distribution:

Molten Salt Test Case

Figure 14. Comparison of DRAC and THRMHYD Steady-State

Circumferential $\left(R=R_{o}\right)$ Tube Wall Temperature

Distribution: Molten Salt Test Case

Figure 15. Comparison of DRAC and Analytical Solution for

Axial Fluid Temperature Distribution: Air Test Case

Figure 16. Comparison of DRAC and Analytical Solution for

Axial Fluid Pressure Distribution: Air Test Case

Figure 17. Transient Response of Maximum Fluid and Tube Wall

Temperatures: DRAC Example Test Case

\section{LIST OF TABLES}

Table I. Summary of Steady-State Modeling Conditions

Table II. Namelist INPUT for Sample Problem 


\section{NOMENCLATURE}

Symbol Description

$\begin{array}{ll}A & \text { Area of flow cross-section } \\ C_{p o} & \text { Ideal gas specific heat } \\ D_{i} & \text { Inside tube diameter } \\ D_{o} & \text { Outside tube diameter } \\ f & \text { Tube wall Moody friction factor } \\ g & \text { Gravitational acceleration } \\ g_{c} & \text { Constant, } 32.174 \mathrm{lbm}-\mathrm{ft} / \mathrm{s}^{2}-\text { lbf } \\ N_{c} & \text { Number of circumferential heat conduction nodes per fluid control volume } \\ & \text { along } R=R_{0} \text { line } \\ N_{c v} & \text { Number of fluid control volumes in DRAC model } \\ N_{E Q} & \text { Number of equations in the DRAC model as defined by equation (1) } \\ N_{R} & \text { Number of radial heat conduction nodes per fluid control volume } \\ & \text { along } \theta_{A}=0^{\circ} \\ P & \text { Fluid pressure } \\ P_{i} & \text { Fluid pressure at inlet boundary } \\ Q & \text { Heat flux per unit area } \\ Q_{p} & \text { Peak incident axial crown flux per unit area } \\ R & \text { Tube wall radial coordinate } \\ R_{i} & \text { Inside tube radius } \\ R_{o} & \text { Outside tube radius } \\ t & \text { Time } \\ T & \text { Fluid temperature } \\ T_{i} & \text { Fluid temperature at inlet boundary } \\ T_{w} & \text { Wall temperature } \\ W & \text { Mass flow per unit time } \\ z & \text { Axial coordinate } \\ Z_{L O N G} & \text { Tube length } \\ \rho & \text { Fluid density } \\ \rho_{i} & \text { Fluid density at inlet boundary } \\ \theta & \text { Tube orientation angle with respect to the horizontal } \\ \theta_{A} & \text { Tube wall angular coordinate } \\ & \end{array}$




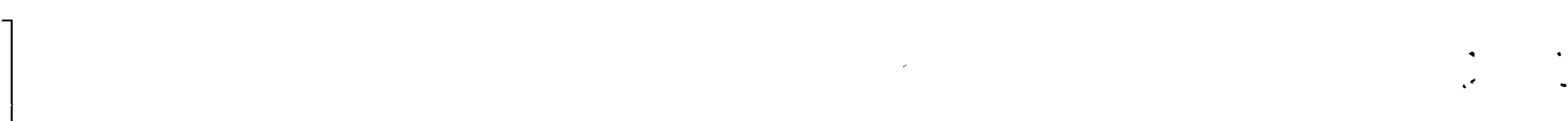
: 


\section{DRAC - A User Friendly Computer Code for Modeling Transient}

Thermohydraulic Phenomena in Solar Receiver Tubing

\section{Introduction}

The primary purpose of this report is to document the computer code DRAC (Dynamic Receiver Analysis Code). The report contains an overall description of the code, a comprehensive set of validation calculations, and detailed description of how to use the code.

DRAC models a fluid-flow/heat transfer configuration frequently encountered in the design and use of solar central receivers, namely, the absorbtion of redirected solar heat flux from the heliostat field into a moving receiver fluid. DRAC is capable of determining transient as well as steady state tube wall and fluid temperatures during operation. The user specifles arbitrary incident heat flux and flow rate disturbances for a single tube. DRAC then calculates the resulting tube wall cross sectional temperature profiles and fluid properties as a function of axial position and time.

The steady-state predictive capabilities of DRAC are similar to Thermohydraulic (THRMHYD), a computer code developed at Sandia, Livermore. However, DRAC contains substantial improvements in the way heat losses (convective and radiative) and compressible flows effects are treated. These improvements are discussed in the following sections.

DRAC is not a self contained code, but rather a "user friendly" interface to TOPAZ and DASSL, two general purpose codes, developed at SNLL. The first of the codes, TOPAZ, (Transient One Dimensional Pipe Flow Analyzer Code) was written by the present author for the purpose of modeling a highly general class of transient problems encountered in the design and evaluation of solar central receiver components and systems. The code is similar to the presently existing family of nuclear reactor accident analy sis codes (e.g., references 1,2 ) in the way the fluid flow is modeled. Such codes have proven successful in modeling water/steam receiver flows (e.,g., see references 3,4$)$. 
Both TOPAZ and the nuclear codes permit modeling of an arbitrary arrangement of one-dimensional, transient flows including branching, closed loops, cocurrent, and counter current flows. Unlike the nuclear codes, TOPAZ can also model two-dimensional, transient heat conduction in the fluid containment. Furthermore, special provisions have been made to include the "solar boundary conditions" (radiative and convective boundary conditions). Unlike the nuclear codes, TOPAZ is specially suited to treat arbitrary working fluids both incompressible (e.g., molten salt, liquid sodium, etc.) and compressible (e.g., air, He, water-steam, etc.). In addition, the code is highly modular permitting treatment of new components, control equations, and fluids, as the need arises. More detailed documentation of TOPAZ is left to a future SAND Report.

The primary draw back in the application of TOPAZ is that the code is not "user friendly". In order to retain the codes' generality an extremely complex and programmer intensive user interface code would have to be written. Such general user interface could, as in the case of the nuclear codes, take many man years of effort to develop. Since an undertaking of this magnitude is inappropriate for the Solar Program, an alternate approach is being taken in which a number of less general user interface programs are written for the purpose of treating specific classes of problems. DRAC represents the first of these user friendly interfaces to be developed to date. As the need arises, interface programs for solving different classes of problems can be developed with comparitively little effort (man-days to man-weeks).

The relationship between DRAC, TOPAZ, and DASSL is illustrated in Figure 1. The user provides a concise set of namelist input data to DRAC. DRAC then generates a computational mesh compatible with the TOPAZ subroutines. The computational mesh represents a recipe for TOPAZ to use in spatially discretizing the partial differential conservation equations. Once this task has been completed, all that remains is for the numerical integrator, DASSL, to integrate the resulting system of ordinary differential equations in time.

DASSL [5] is a family of mathematical subroutines which performs fully implicit integration of systems of ordinary differential equations. The time step is automatically selected to provide efficient integration while maintaining the user specifled error tolerances. DASSL was found to be especially well suited to integrating the TOPAZ equations. 


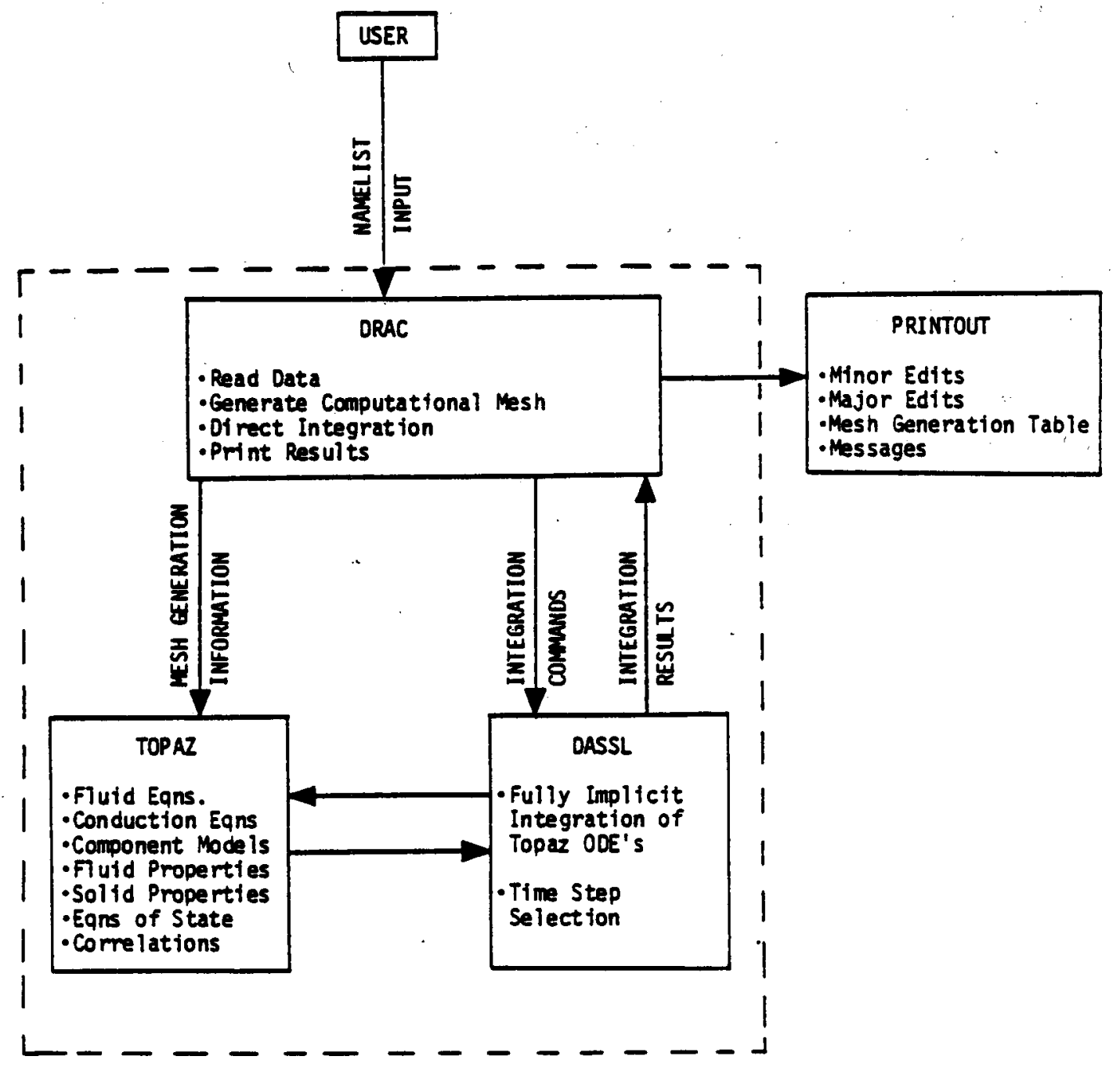

Figure 1.

DRAC-TOPAZ-DASSL Code Architecture. 
During integration of the system of equations, control periodically returns to DRAC which then provides major and minor edits (printouts) of the system dependent variables. The frequency of major and minor edits is selected by the user and is read in a part of the namelist input. DRAC continues to direct the integration by repetitive calls to DASSL until a user specified time has been reached at which point calculations are stopped. DRAC also prints out useful error messages and a Mesh Generation Table which identifies the location and type of each system variable. This table is extremely useful in interpreting information given in the major and minor edits.

Section II of this report contains a more detailed description of the class of problems solved by DRAC. In Section III steady-state solutions predicted by DRAC are compared to known solutions, including those generated by THRMHYD. Section VI contains a detailed description of how to use DRAC together with an example transient calculation. Concluding remarks and a brief discussion of future activities are presented in Section $V$. 


\section{DRAC Description}

\section{A. The DRAC Problem}

The fluid flow/heat transfer conflguration modeled by DRAC is illustrated in Figure 2. A heat transfer fluid enters a single receiver tube where it is heated by incident solar flux. The user specifies a constant inlet temperature, a time dependent inlet mass flow rate, an exit pressure, and a time dependent peak solar flux, $Q_{P}$. The code then calculates the one-dimensional, transient fluid temperature, pressure, and mass flow profiles $T(z, t), P(z, t)$, and $W(z, t)$ respectively. (See reference 6 for a presentation of the fluid flow equations.) The two-dimensional, transient tube wall temperature distribution, $T_{w}\left(z, R, \theta_{A}, t\right)$, is also calculated with axial conduction effects neglected.

As illustrated by Figure 2b, a line of symmetry for the conduction solution is assumed. The line of symetry extends from the front crown to the back crown of the tube. Additional assumptions for this problem may be summarized as follows:

- The receiver tube is tilted at an angle $\theta$ with respect to the horizontal.

- The back of the receiver tube is perfectly insulated as shown in Figure 2.

- The receiver tube heat transfer is not influenced by the presence of adjacent receiver tubes in the panel.

- The incident axial heat flux profile shown in Figure 2 a remains similar although the peak heat flux value $Q_{p}$ may vary with time.

- The incident heat flux is projected onto the outer tube wall according according to the cosine distribution shown in Figure $2 \mathrm{~b}$.

- Losses from the outer tube wall are calculated from the local outer tube wall temperature. These losses include radiative (emission and reflection) as well as convective losses. The heat transfer coefficient, emissivity, and absorptivity are currently taken as constant.

- Axial heat conduction in the fluid as well as tube wall are neglected. 

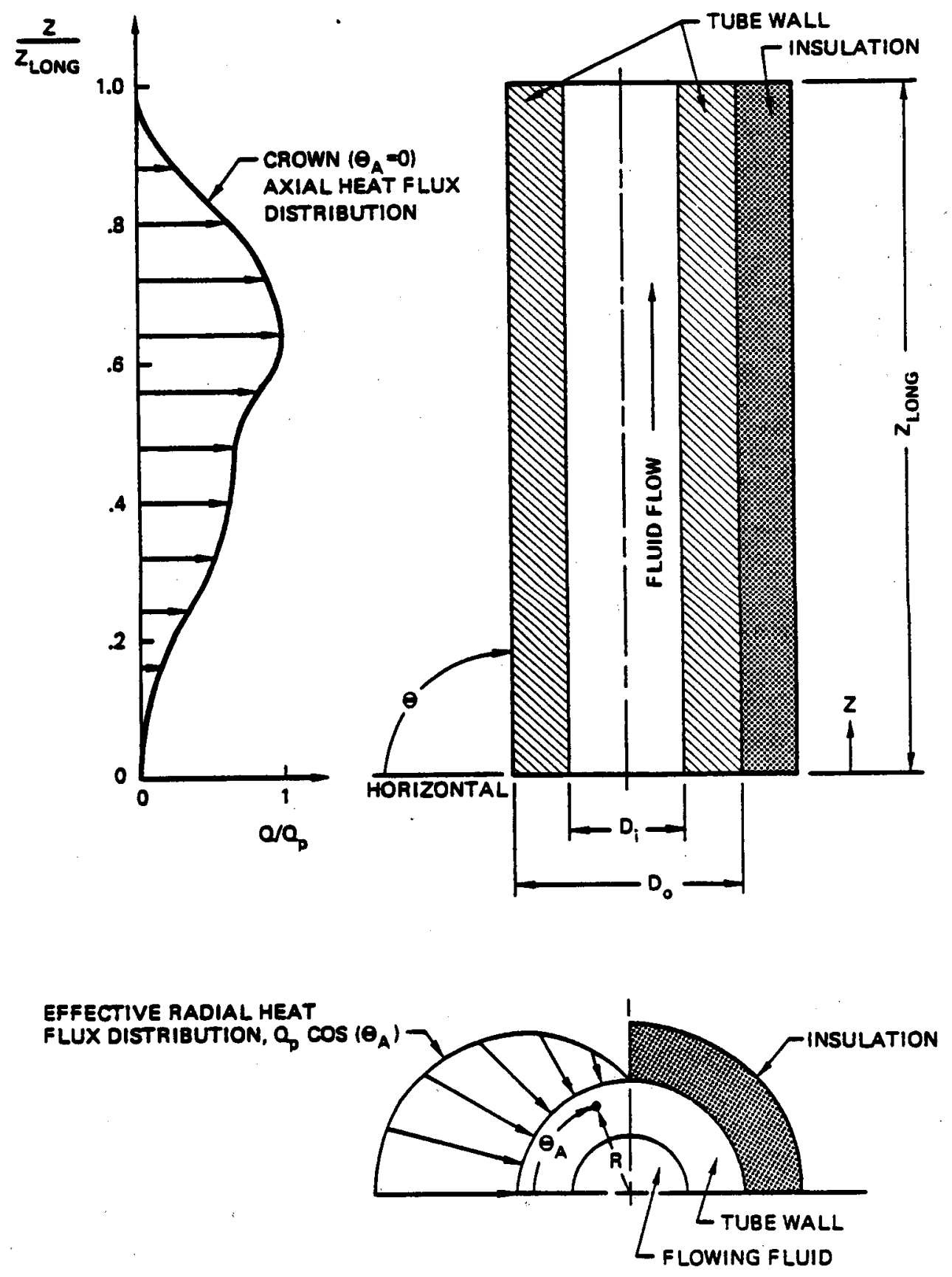

Figure 2.

Schematic of the DRAC Model. 
- Two-dimensional fluid flow effects are accounted for through the use of use of heat transfer and friction factor correlations for tube flow. Currently, all inside tube surfaces are assumed smooth.

- Currently, properties for the following fluids are "hardwired" into the TOPAZ fluid property subroutines: air with constant and variable $C_{p}$, liquid sodium, molten draw salt, helium ( $\mathrm{He}^{3}$ and $\left.\mathrm{He}^{4}\right)$, hydrogen, deuteriuum, and tritium. Other fluids may be added with little effort as the need arises.

- Any tube wall material may be modeled (including temperature dependent thermal properties). Currently properties for 18-8 Stainless and Incoloy-800 are "hardwired" into the TOPAZ solid property subroutines. Other solid material properties may be easily added as the need arises.

It should be pointed out that nearly any or all of the above assumptions and restrictions may be relaxed by creating slightly different versions of DRAC. A version, for example, could be written which accounts for heat loss out the back side of the tube, or an axial flux distribution which is not similar with time, or even a control algorithm which specifies inlet mass flow as a function of any variables in the model.

\section{B. Mesh Generation}

Details of the conduction and fluid flow equations as well as the numerical technique used in descritizing the equations in space will be published in a future SAND report documenting TOPAZ. These details are not essential to an understanding of DRAC capabilities, or its use. However, the DRAC user must be somewhat familiar with the way the computational mesh is generated in order to interpret some of the printed results (major and minor edits).

DRAC subdivides the computational space (solid tube and flowing fluid) into 4 different types of nodes. These node types may be summarized as follows:

1. Continuity node

2. Energy node

3. Momentum node 


\section{Solid Conduction node}

The above four nodes are a consequence of spatially discretizing the following four conservation equations respectively:

1. One-dimensional transient fluid continuity equation

2. One-dimensional transient fluid energy equation

3. One-dimensional transient fluid momentum equation

4. Two-dimensional transient solid heat conduction equation.

The nodalization of the fluid space is illustrated in Figure 3 . It is helpful to think of the fluid as being divided up into $N_{c v}$ control volumes connected by momentum "stream tubes". Continuity and energy nodes (circles) are physically located in the same axial locations at the center of each control volume while momentum nodes (squares) are displaced such that they lie at the control volume interfaces. This displaced mesh scheme is similar to that used in nearly all nuclear codes such as RELAP [1] and RETRAN [2].

In DRAC the only exceptions to the displaced mesh arrangement occur at the boundaries. The first three nodes all lie on the upstream boundary of the first fluid control volume. Similarly, the last three nodes all lie on the downstream boundary of the last fluid control volume.

The user is free to specify the number of control volumes, $N_{c v}$, to be used in the computation. Each additional interior control volume specified by the user adds one momentum node, one continuity node, and one energy node to the model. 


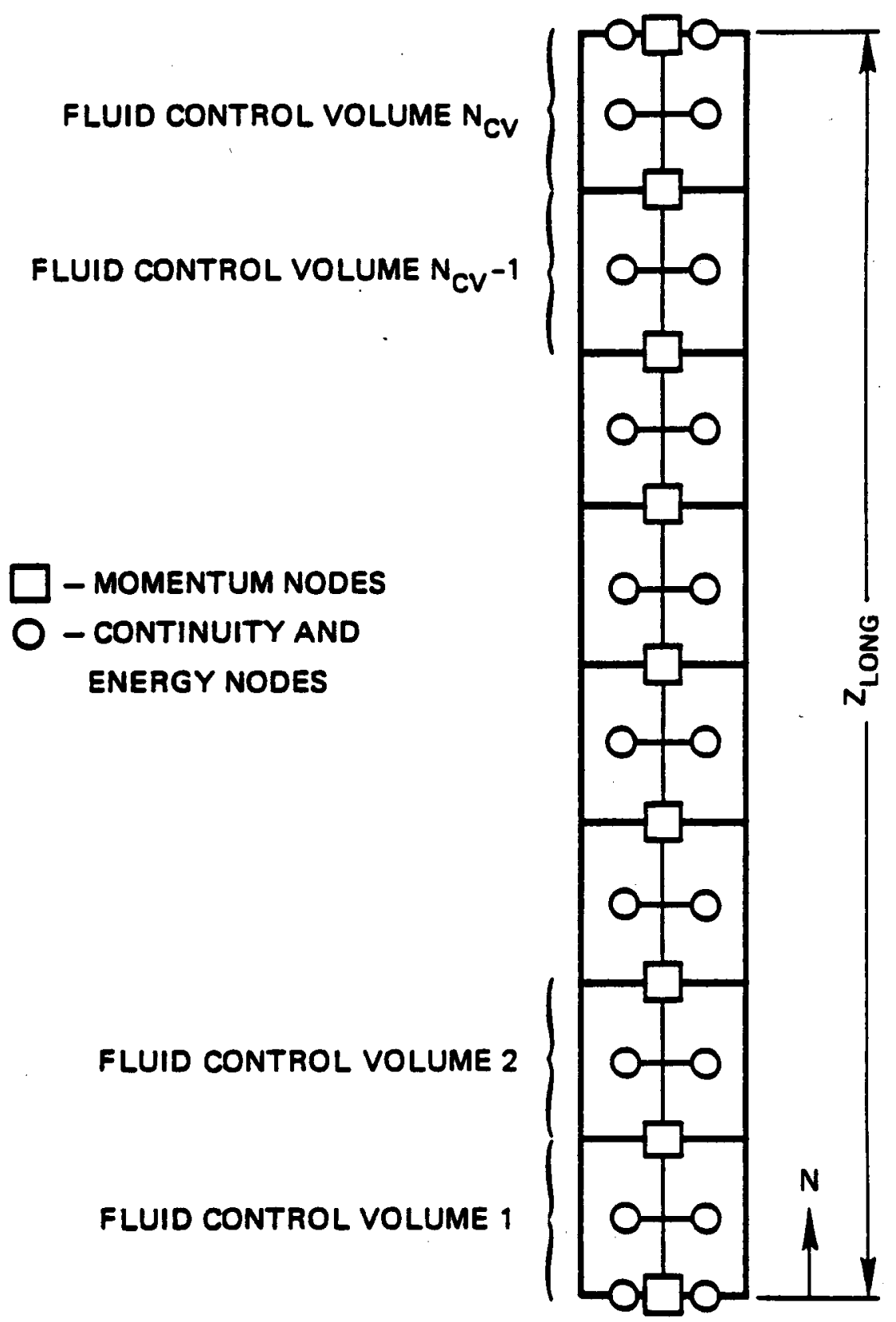

Figure 3.

Spatial Nodalization of the Fluid Stream. 
Corresponding to each interior fluid control volume specified by the user, is a set of tube wall conduction nodes. Figure 4 illustrates the nodalization of the tube wall adjacent to an interior fluid control volume. The user inputs two constants $N_{R}$ and $N_{c}$ to completely specify the nodalization of the tube cross section. $N_{R}$ represents the number of "radial" heat conduction nodes and $N_{c}$ represents the number of "circumferential" heat conduction nodes. The situation illustrated in Figure 4 correspondes to $\mathrm{N}_{R}=5$ and $\mathrm{N}_{c}=5$. The mesh generator in DRAC positions conduction nodes along the interior and exterior tube wall surface as well as within the tube wall itself. In general, DRAC attempts to position the greatest number of nodes in the front of the tube wall where the thermal gradients tend to be the most severe. With the exception of the nodes along the lines $\theta_{A}=0^{\circ}$ and $\theta_{A}=180^{\circ}$, the volumes represented by each node are approximately equal. The user must specify values of $N_{R}$ and $N_{c}$ of at least 3 .

The total number of equations which make up a DRAC model may be determined directly from the user specified $N_{c v}, N_{R}$, and $N_{c}$. The formula for the total number of equations (nodes) in the model may be written as:

$$
N_{E Q}=5+N_{c v}\left(3+N_{R} \times N_{c}\right)
$$

where

$$
\begin{array}{ll}
N_{E Q} & =\text { total number of equations (nodes) in the model } \\
5 & =\text { number of boundary equations (nodes) } \\
N_{c v} & =1 \text { number of fluid control volumes } \\
3 & \text { volume }
\end{array}
$$

If a user specifies $N_{c v}=3, N_{R}=3$, and $N_{c}=3$ the total number of equations in the model would then be $N_{E Q}=41$. DRAC would automatically generate a computational mesh, store user input data and connectivity information in required arrays and pass this information to the TOPAZ subroutines (See Figure 1). For this particular case the resulting nodal numbering is illustrated by Figure 5. DRAC also prints a mesh generation table as part of the output. This table identifies the type and location of all nodes and enables the user to interpret printouts of nodal dependent variables as a function of time. 


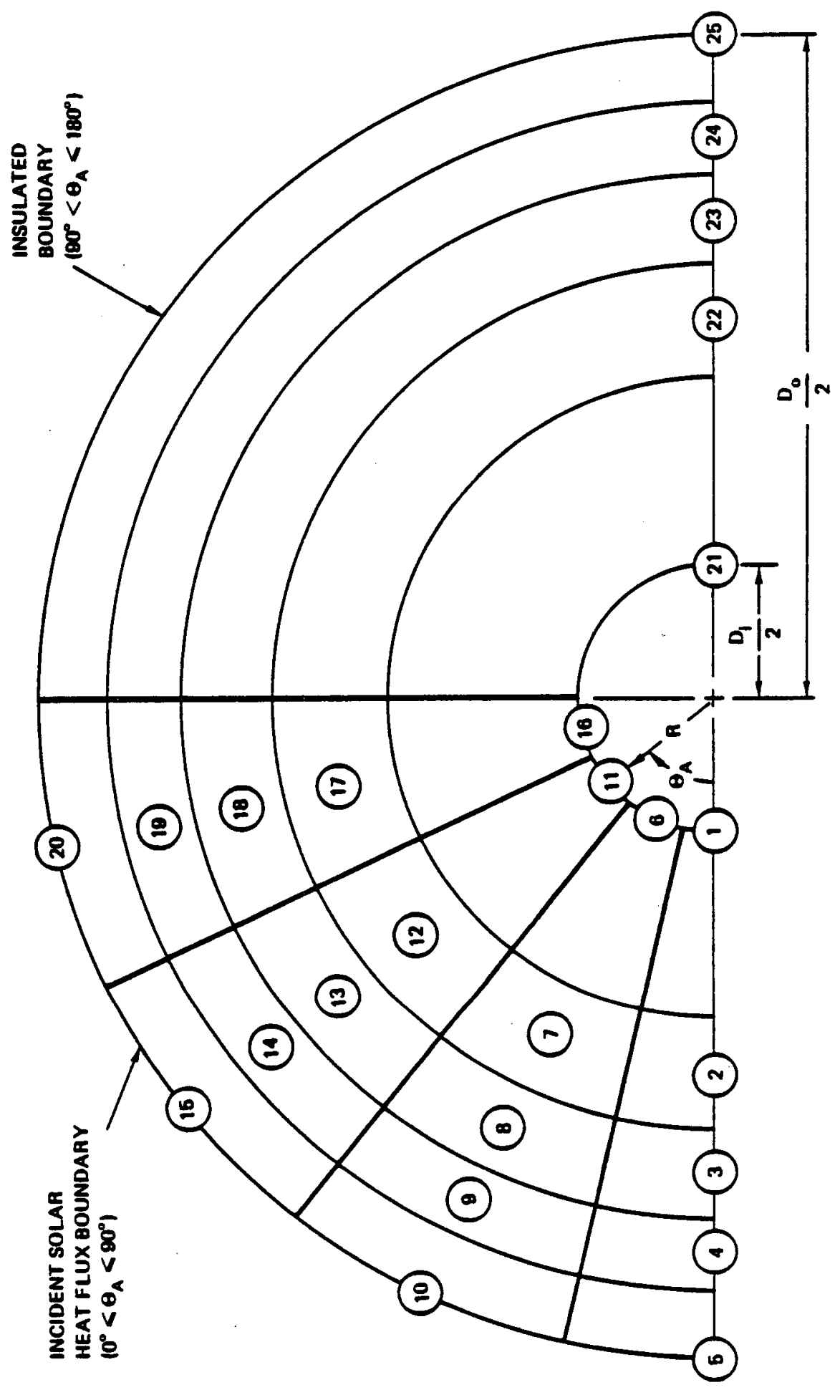

Figure 4.

Spatial Nodalization of the Tube Wall 


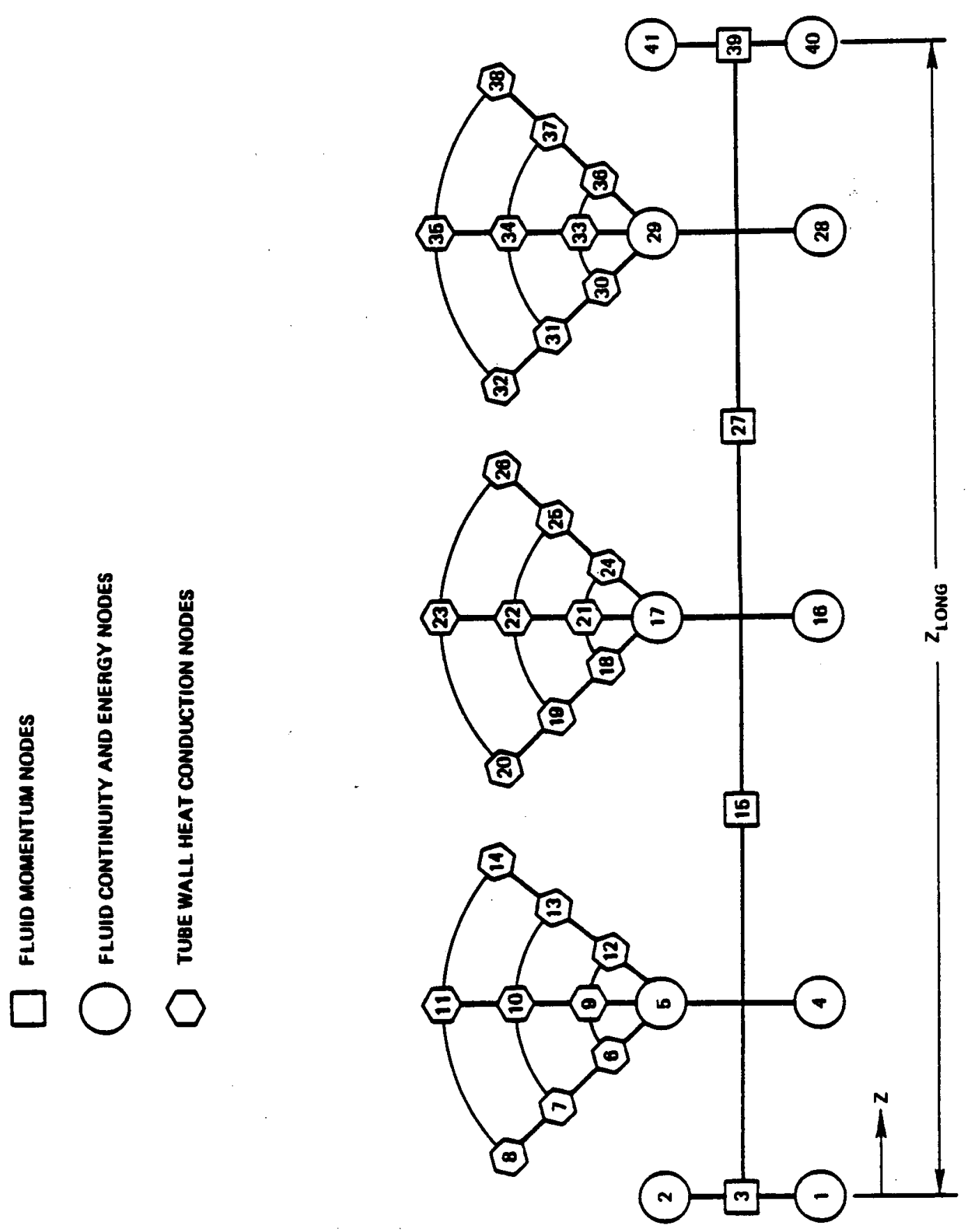

Figure 5.

Nodal Numbering for $N_{c v}=N_{R}=N_{c}=3$. 


\section{DRAC Steady-State Validation Calculations}

DRAC predictions for several receiver tube heat transfer/fluid flow situations are presented in this section. In all cases the predictions are made for various steadystate operating conditions. The steady-state calculations enable a direct comparison between DRAC and THRMHYD, the latter code being exclusively intended for steady-state calculations. The comparisons between the two codes are made for two incompressible flow situations, namely molten salt and liquid sodium cooled receivers.

A steady-state highly compressible (Mach number $\simeq .5$ ) flow situation is also modeled by DRAC and comparisons are made with an analytical solution.

Comparisons made in this section include the following:

- Fluid temperature as a function of axial position

- Fluid pressure drop as a function of axial position

- Tube wall outer crown temperature as a function of axial position

- Radial and circumferential tube wall temperature distributions at a particular axial position

These comparisons are intended to demonstrate the capabilities of DRAC and to provide some measure of confidence in DRAC's calculational results.

All computations with THRMHYD were made with 100 fluid control volumes which was found to be more than adequate to resolve the fluid flow problem. The maximum number of control volumes used in the DRAC computations was 20 and several computations were performed with as few as 10 control volumes.

Unlike DRAC, which solves the tube wall heat conduction problem using a numerical finite difference technique, THRMHYD utilizes the closed form analytical two-dimensional steady-state heat conduction solution. (Both codes neglect axial conduction.) The ability of the DRAC numerical solution to approach the actual analytical solution depends directly on the number of tube wall cross-sectional conduction nodes (i.e., $N_{R}$ and $N_{c}$ ). The number of conduction nodes used in the 
comparisons here was varied from a minimum of $9\left(N_{R}=N_{c}=3\right)$ to a maximum of $27\left(N_{R}=3, N_{c}=9\right)$.

The axial heat flux distribution selected for the calculations was that shown in Figure 6, except for the compressible air flow calculations, in which a uniform axial heat flux distribution was used. The remaining conditions for the steady-state modeling calculations are summarized in Table I.

One of the major features of DRAC is its ability to predict steady-state solutions (and hence initial conditions for transient simulations) from nearly any unsteady starting condition. The code begins from a fictitious zero heat flux, zero flow rate condition. The heat flux and flow rate are then automatically increased over the first second of real time until they reach the user specified levels. From that time on, one need only wait for starting transients to die out leaving the desired steady-state condition. For the incompressible and compressible test cases presented here, the simulation reached steady-state after 30 and 100 seconds of real time, respectively. This feature is of considerable value since the user need never be burdened with computing a complicated set of initial conditions in order to start the code.

Let us first consider the steady-state solutions for the liquid $\mathrm{Na}$ test case. Figure 7 compares DRAC and THRMHYD solutions for axial fluid and outside tube wall crown temperatures. The axial fluid pressure drop solutions are compared in Figure 8. The 20 control volumes used in the DRAC modeling appear to be adequate for resolving the severe heat flux profile of Figure 6.

The tube wall heat conduction solutions with flowing liquid $N_{a}$ are compared in Figures 9 and 10. The profiles shown in the figures correspond to an axial location where the fluid temperature was $1010^{\circ} \mathrm{F}$ and the crown incident solar flux was 116.2 $\mathrm{Btu} / \mathrm{s}-\mathrm{ft}^{2}$. The circumferential heat flux distribution for this case (and all cases) was that previously illustrated in Figure 2b.

Figure 9 contains comparisons for the temperature vs. normalized radius at $\theta_{A}=0^{\circ}$ while Figure 10 compares the circumferential outside wall temperature distributions. It is interesting to note that the nine $\left(N_{R}=N_{c}=3\right)$ tube wall heat conduction nodes used in the DRAC calculations were sufficient to predict temperatures to within several degrees of the THRMHYD analytical solution. Nine heat conduction nodes per fluid control volume is the fewest wall heat conduction 
nodes permitted by DRAC in any computation, i.e., the user must specify an $N_{R}$ value of at least 3 and an $N_{c}$ value of at least 3.

TABLE I.

SUMMARY OF STEADY-STATE MODELING CONDITIONS

\begin{tabular}{llll}
\hline WORKING FLUID & LIQUID Na & MOLTEN SALT
\end{tabular}

Tube Length

10

10

10

(feet)

Tube I.D.

.05433

.05433

.02

(feet)

Tube

Vertical

Vertical

Vertical

Orientation

Inlet Temp.

550

550

100

$\left({ }^{\circ} \mathrm{F}\right)$

Outlet Pressure

45.98

41.8

100

(psia)

Peak Heat Flux

(Btu/s-ft ${ }^{2}$ )

232.4

277.8

26.9

Axial Heat

Figure 6

Figure 6

Uniform

Flux Profile

Mass Flow

.5

.5

.05 


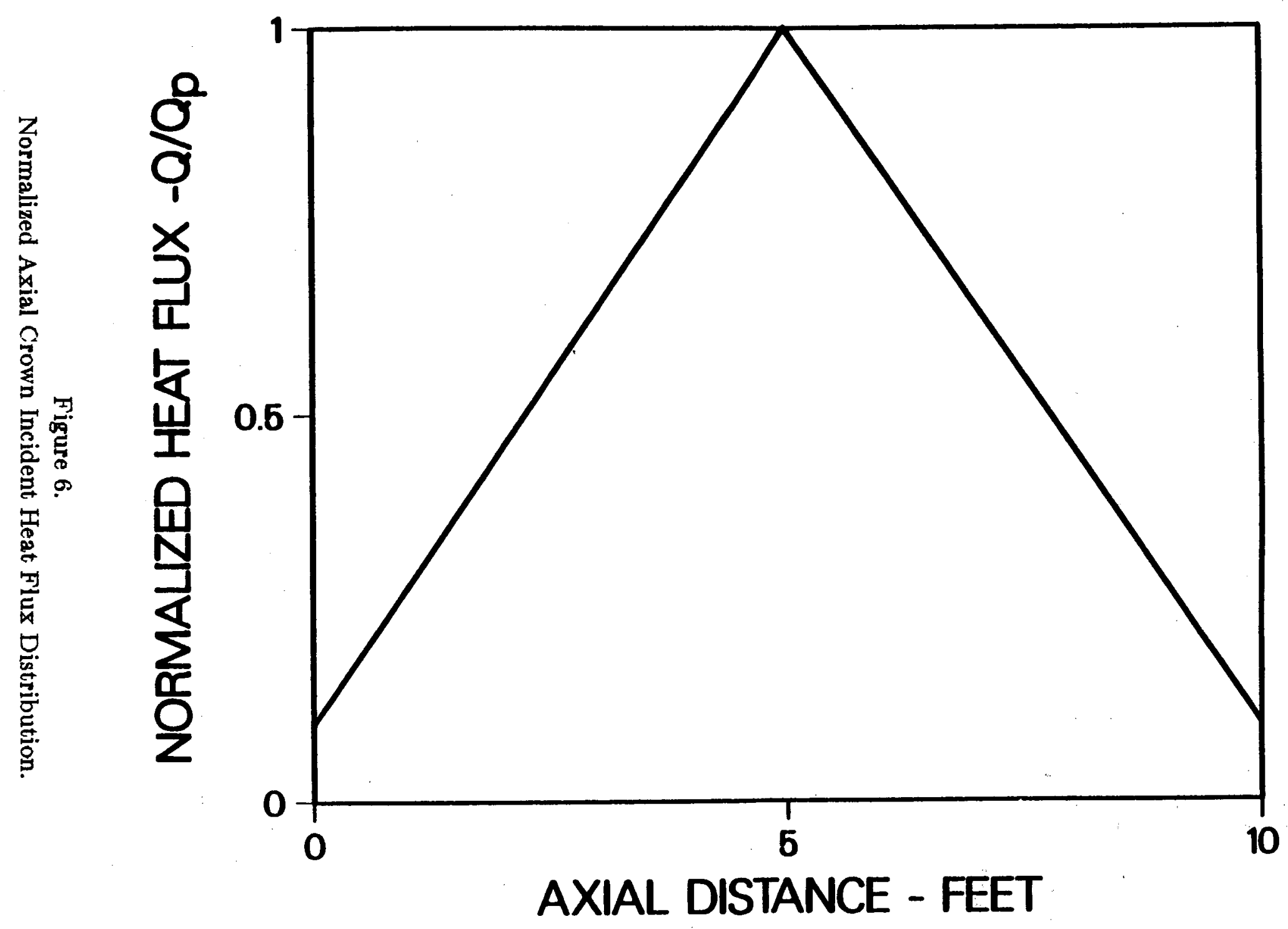




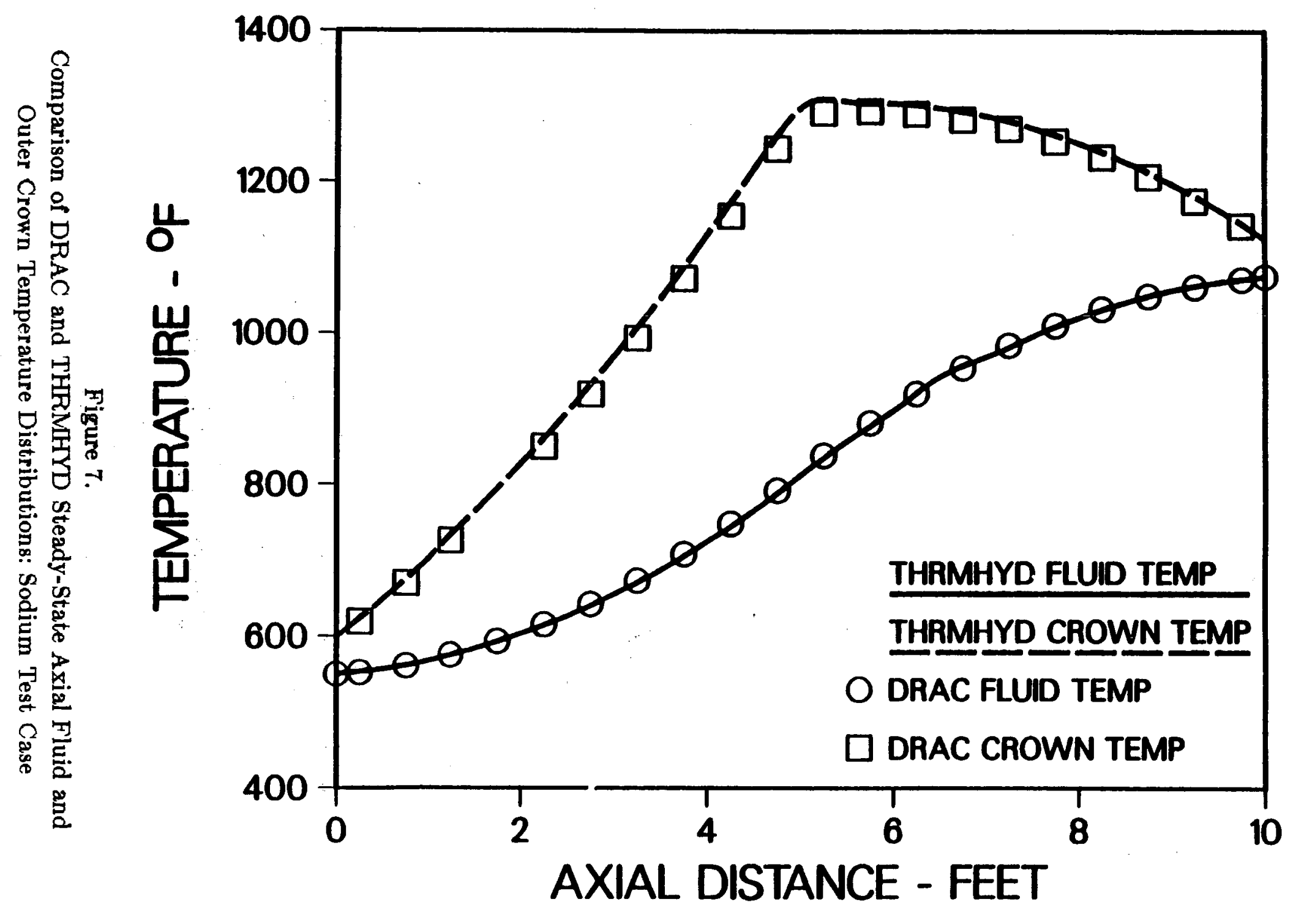



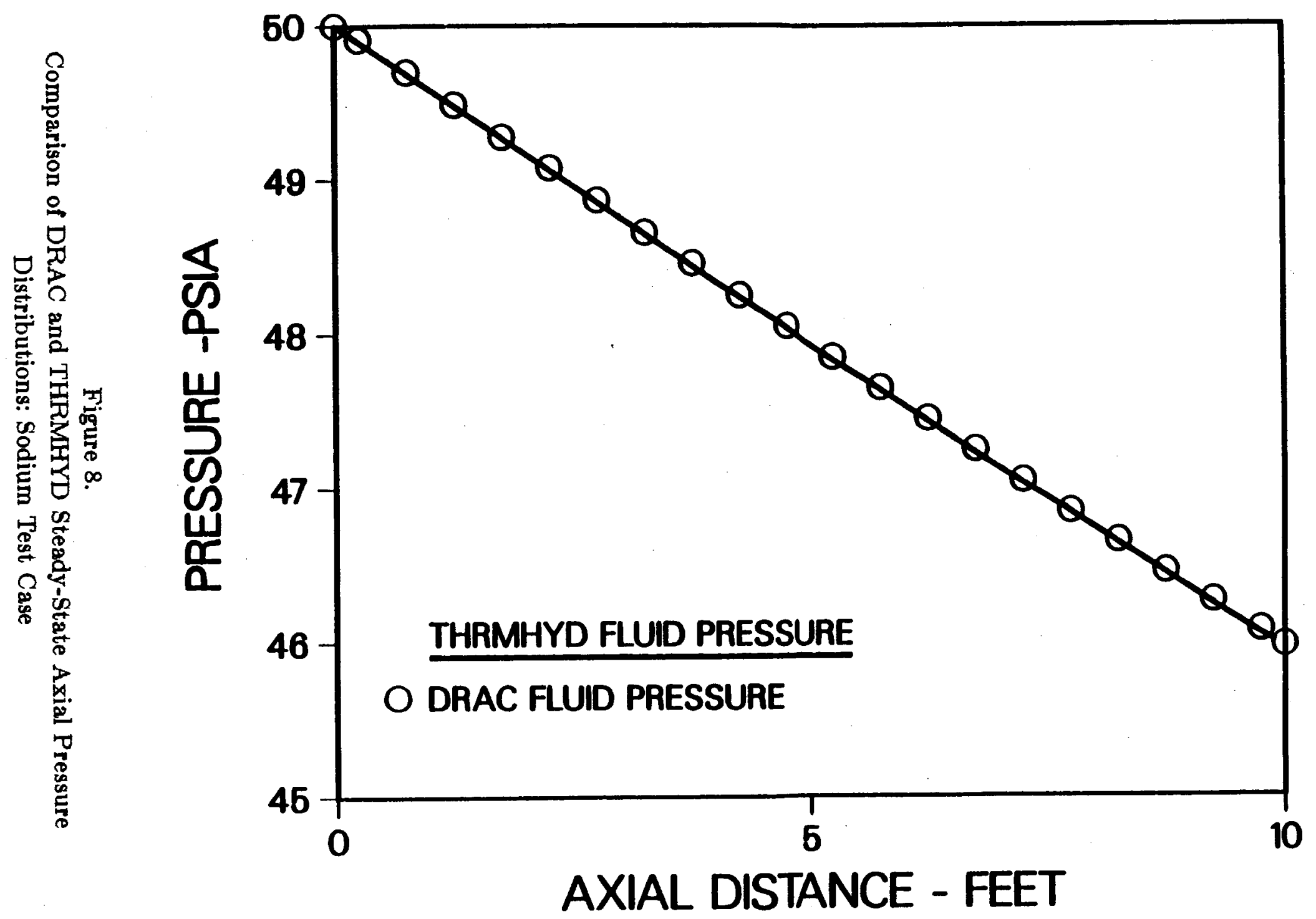


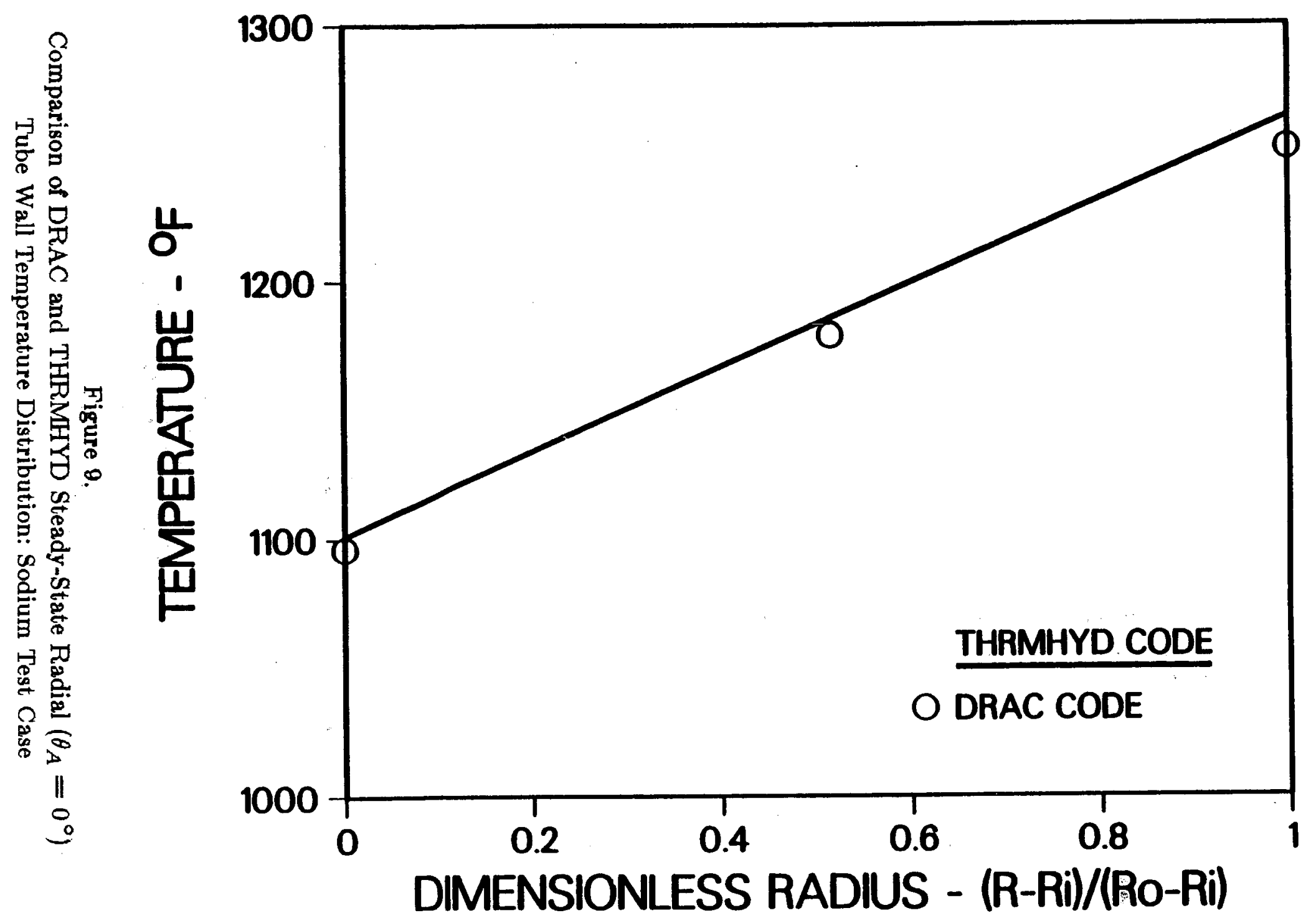




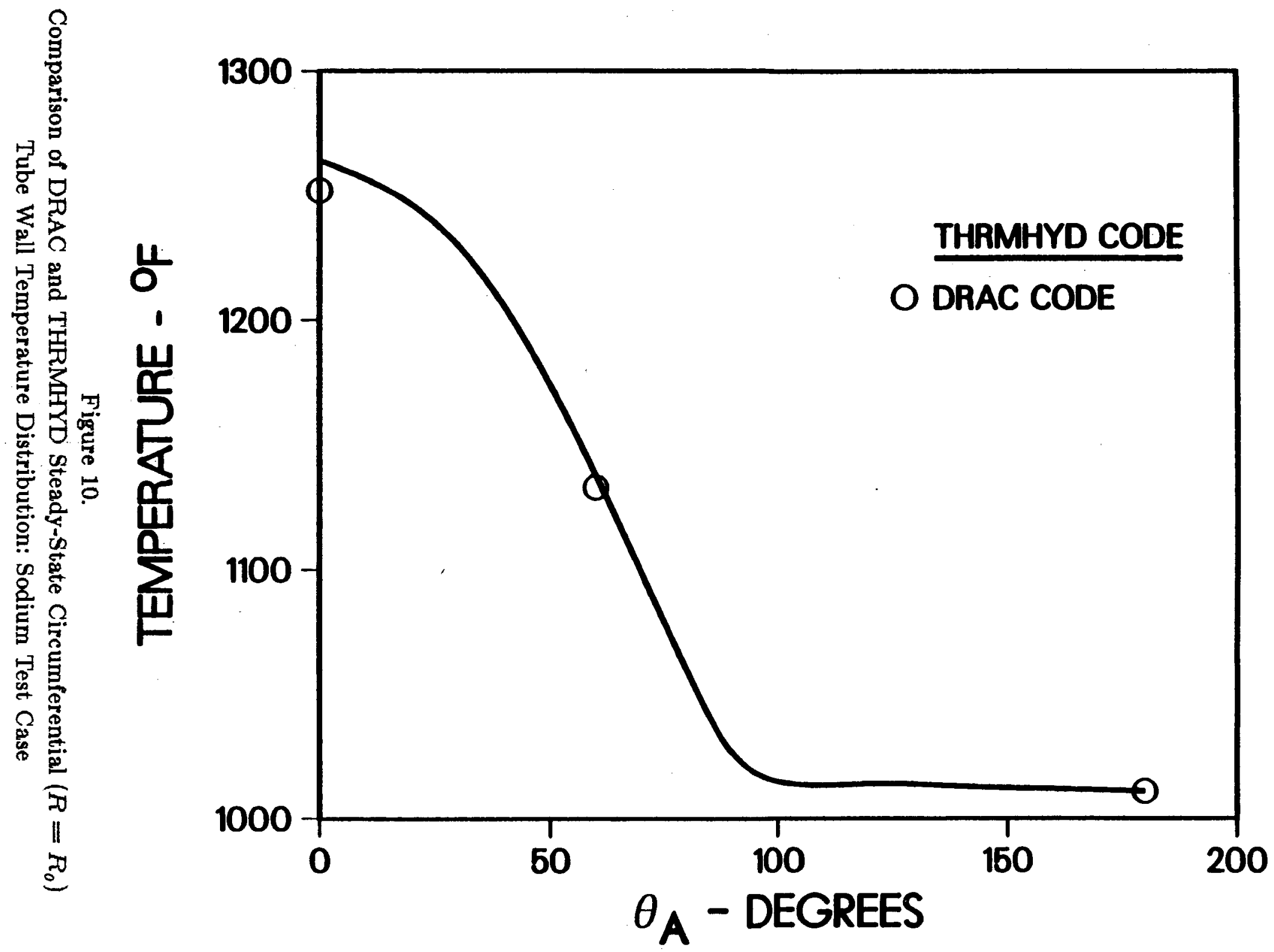


For the molten salt test case the DRAC and THRMHYD solutions for axial fluid and outside tube wall crown temperatures are compared in Figure 11. Figure 12 contains the corresponding comparison for the axial fluid pressure distribution. Here again the 20 control volumes used in the DRAC modeling appear to have been adequate.

Radial $\left(\theta_{A}=0\right)$ and circumferential (outside) tube wall temperature distributions for the salt case are compared in Figure 13 and 14 respectively. Comparisons are made at a tube wall cross section where the flowing salt temperature is $996^{\circ} \mathrm{F}$ and the peak incident heat flux is $138.9 \mathrm{Btu} / \mathrm{s}^{-\mathrm{ft}^{2}}$. In contrast to the sodium case, the minimum nine conduction nodes used in DRAC calculations result in a relatively crude prediction of the temperature profiles. This can be explained by the fact that the heat transfer coefficient for salt flow is considerably lower than that for sodium flow. As a result circumferential temperature gradients in tube walls adjacent to flowing salt tend to be more severe. Resolving these gradients requires additional conduction nodes. The DRAC temperature profiles generated by using $27\left(N_{R}=\right.$ $3, N_{c}=9$ ) conduction nodes per fluid control volume are nearly the same as the profiles predicted analytically by THRMHYD. It quickly becomes apparent that it is not always possible to predict ahead of time how many computational nodes are required to solve a particular problem accurately. Some numerical experimentation may be required by the user in order to insure that solutions generated by DRAC are sufficiently accurate. This is, of course, typical of most numerical solutions.

THRMHYD neglects the kinetic energy terms in the fluid energy equation. Because of this it is not possible to use THRMHYD to model highly compressible steady-state flows. For the highly compressible air flow test case considered here (Mach Number $\simeq .5$ ), the steady-state outlet air temperature predicted by THRMHYD exceeded the corresponding prediction of the analytical solution by more than 7\%. Because of this, the DRAC calculated axial pressure and temperature profiles were compared directly to the steady-state analytical solution rather than THRMHYD predictions. 


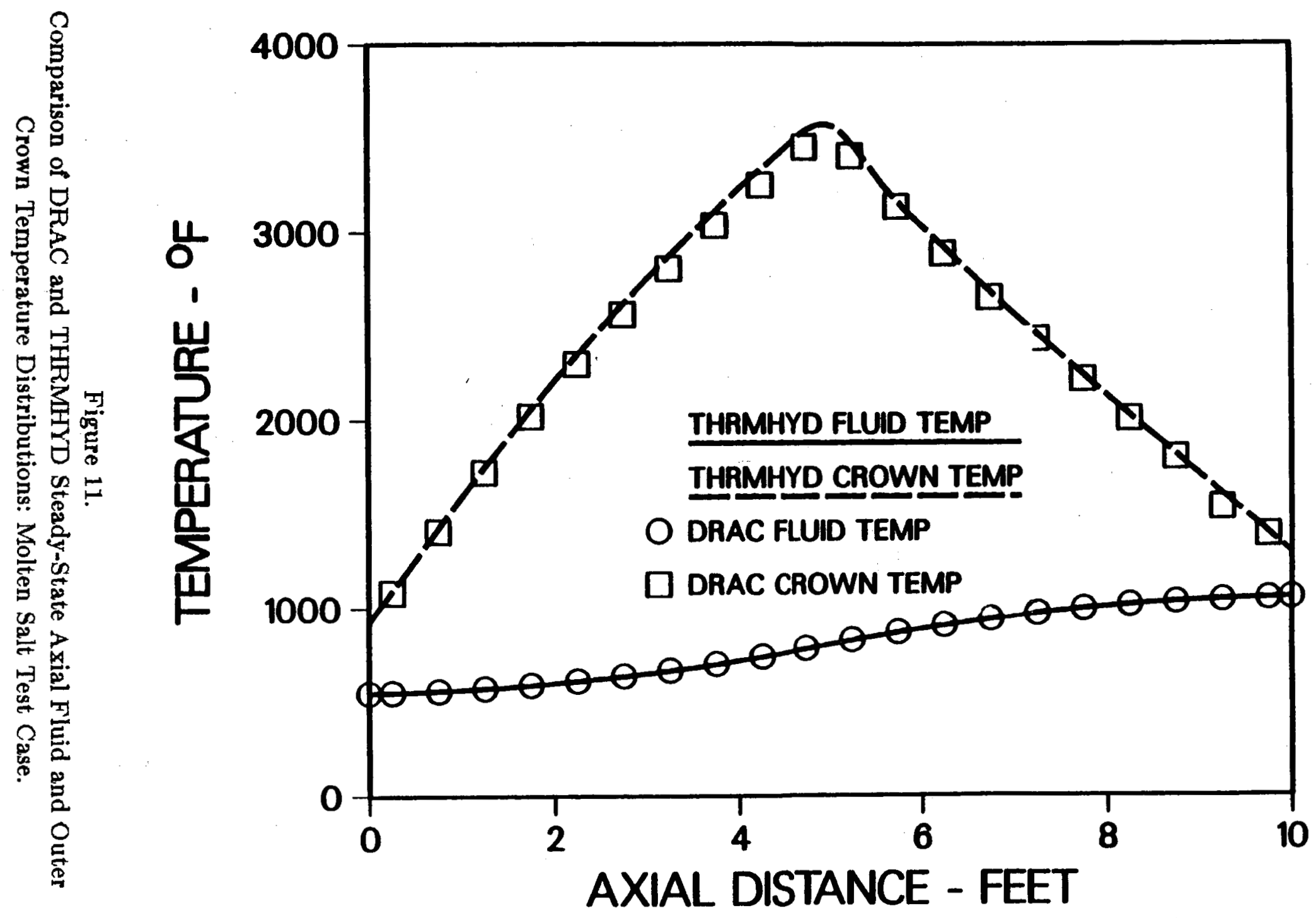




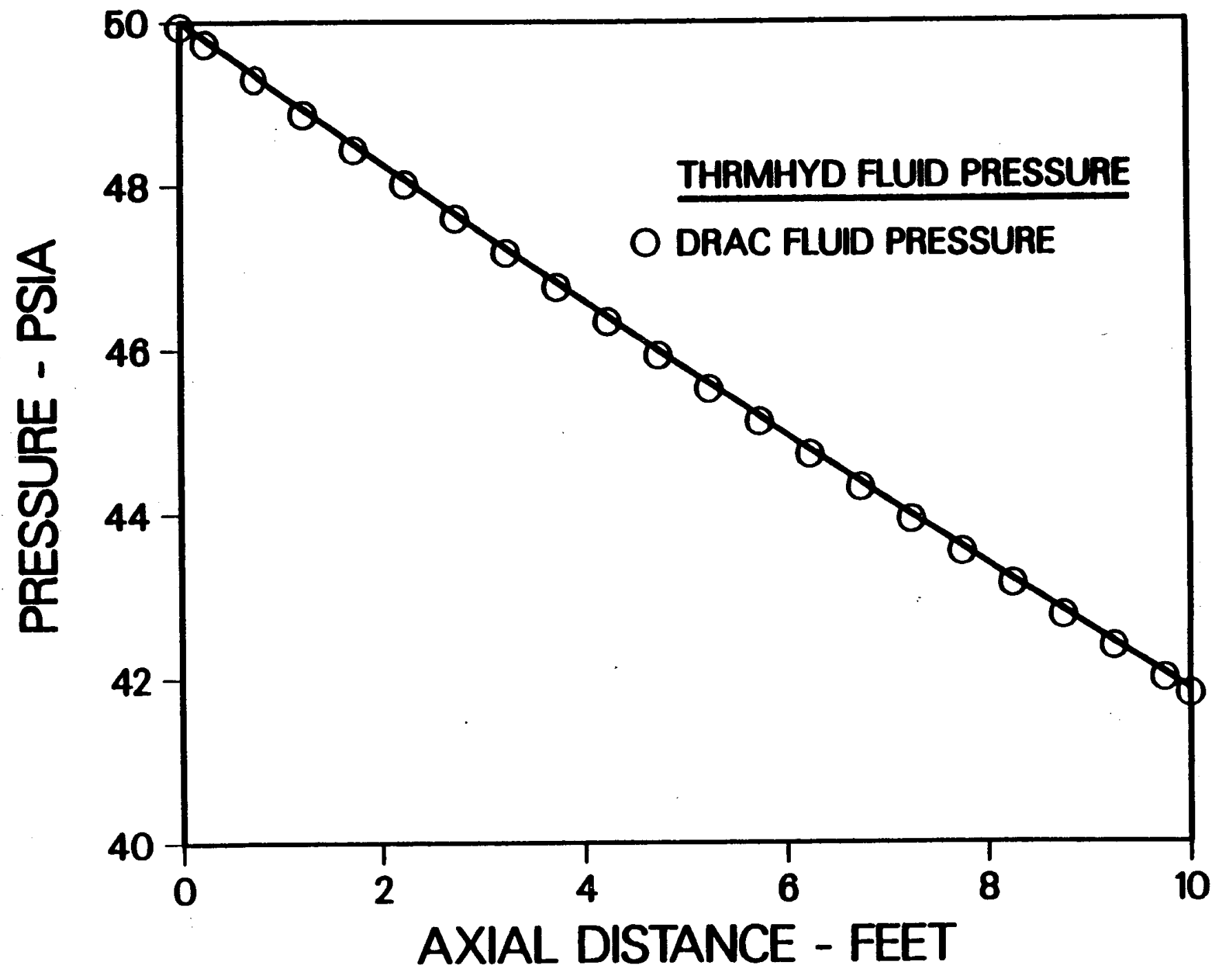




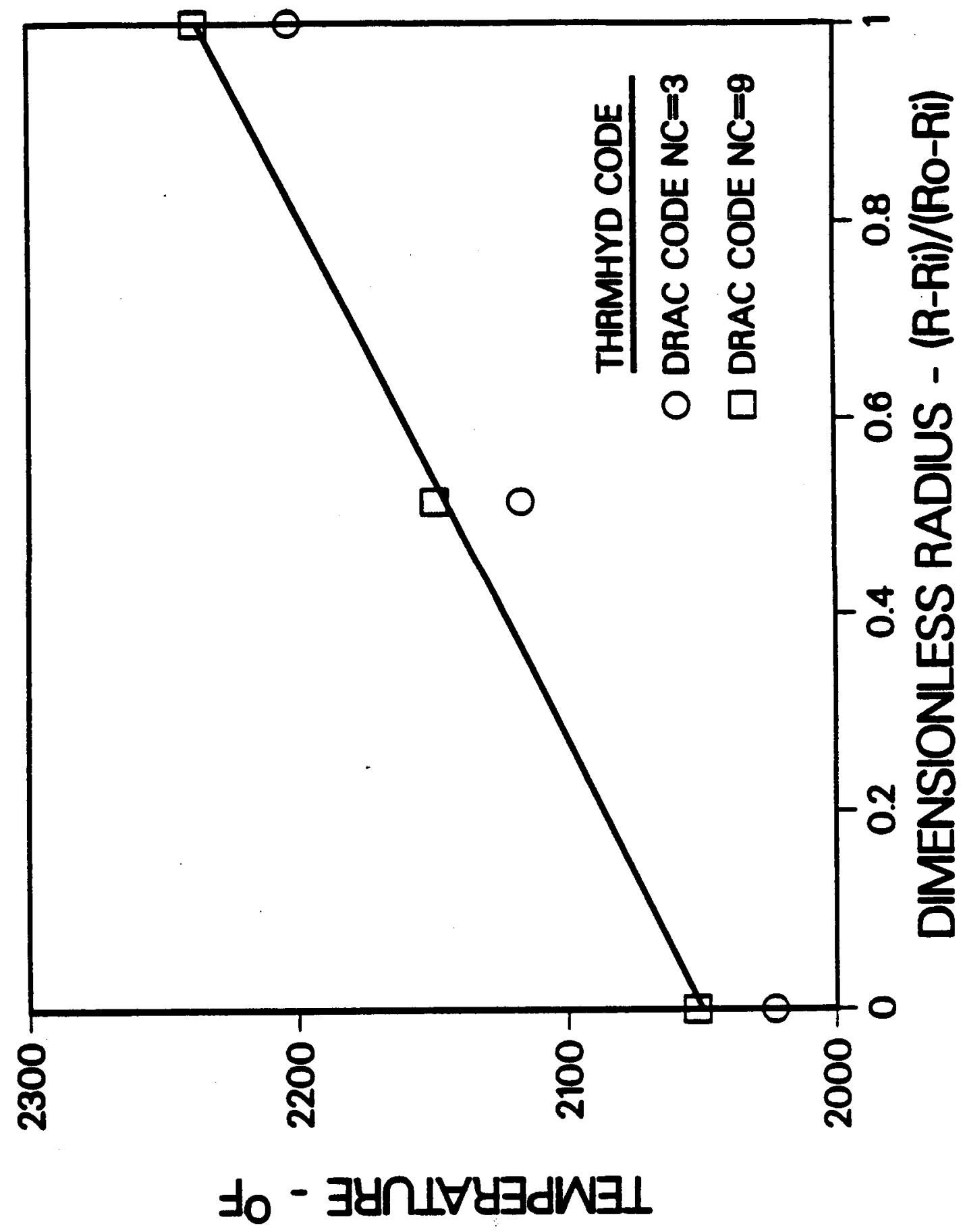

Figure 13.

Comparison of DRAC and THRMHYD Steady-State Radial $\left(\theta_{A}=0^{\circ}\right)$ Tube Wall Temperature Distribution: Molten Salt Test Case 

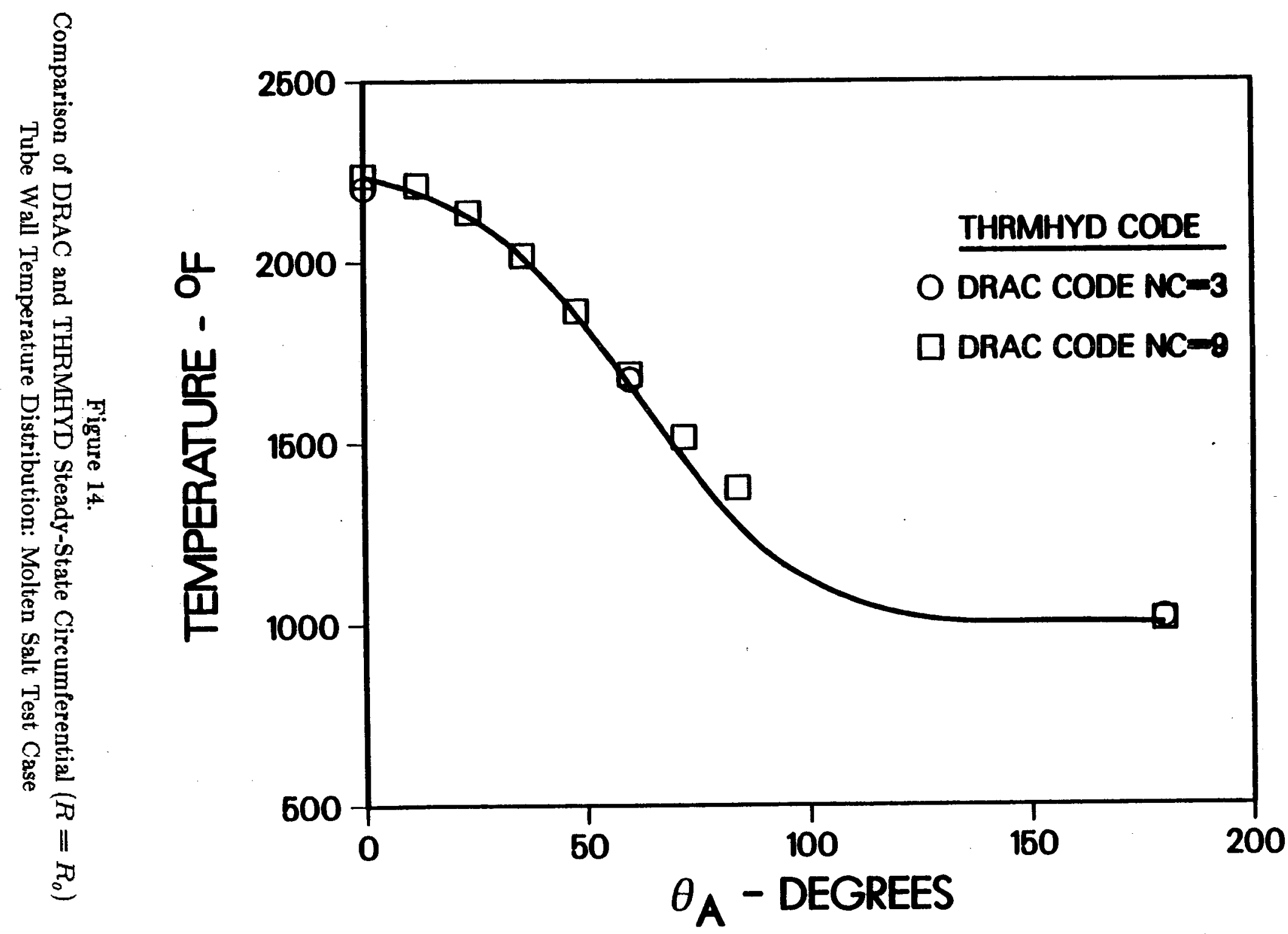
The equations which describe the steady compressible flow of an ideal gas (air with constant specific heat) in the presence of a uniform axial heat flux distribution (no heat losses) and friction may be summarized as follows:

continuity:

$$
W=\text { constant }
$$

momentum:

$$
\frac{W^{2}}{A^{2}}\left[\frac{1}{\rho(z)}-\frac{1}{\rho_{i}}\right]-g_{c}\left[P_{i}-P(z)\right]+\frac{W^{2}}{4 A^{2} D_{i}} \int_{0}^{z} \frac{f(z)}{\rho(z)} d z+g z \rho(z)=0
$$

energy:

$$
W C_{p o}\left[T(z)-T_{i}\right\rfloor+\frac{W^{3}}{2 g_{c} A^{2}}\left[\frac{1}{p^{2}(z)}-\frac{1}{p_{i}}\right]+\frac{W g z}{g_{c}}=D_{o} z Q_{p}
$$

state:

$$
P(z)=\rho(z) R T(z)
$$

where $\rho_{i}, T_{i}$, and $P_{i}$ are inlet density, temperature, and pressure respectively. The analytical solutions for the air temperature, $T(z)$, and pressure, $P(z)$, are compared to corresponding DRAC solution in Figures 15 and 16 respectively. As was the case with the previous incompressible flow comparisons, 20 fluid control volumes appears to be adequate in resolving the compressible flow temperature and pressure profiles. 


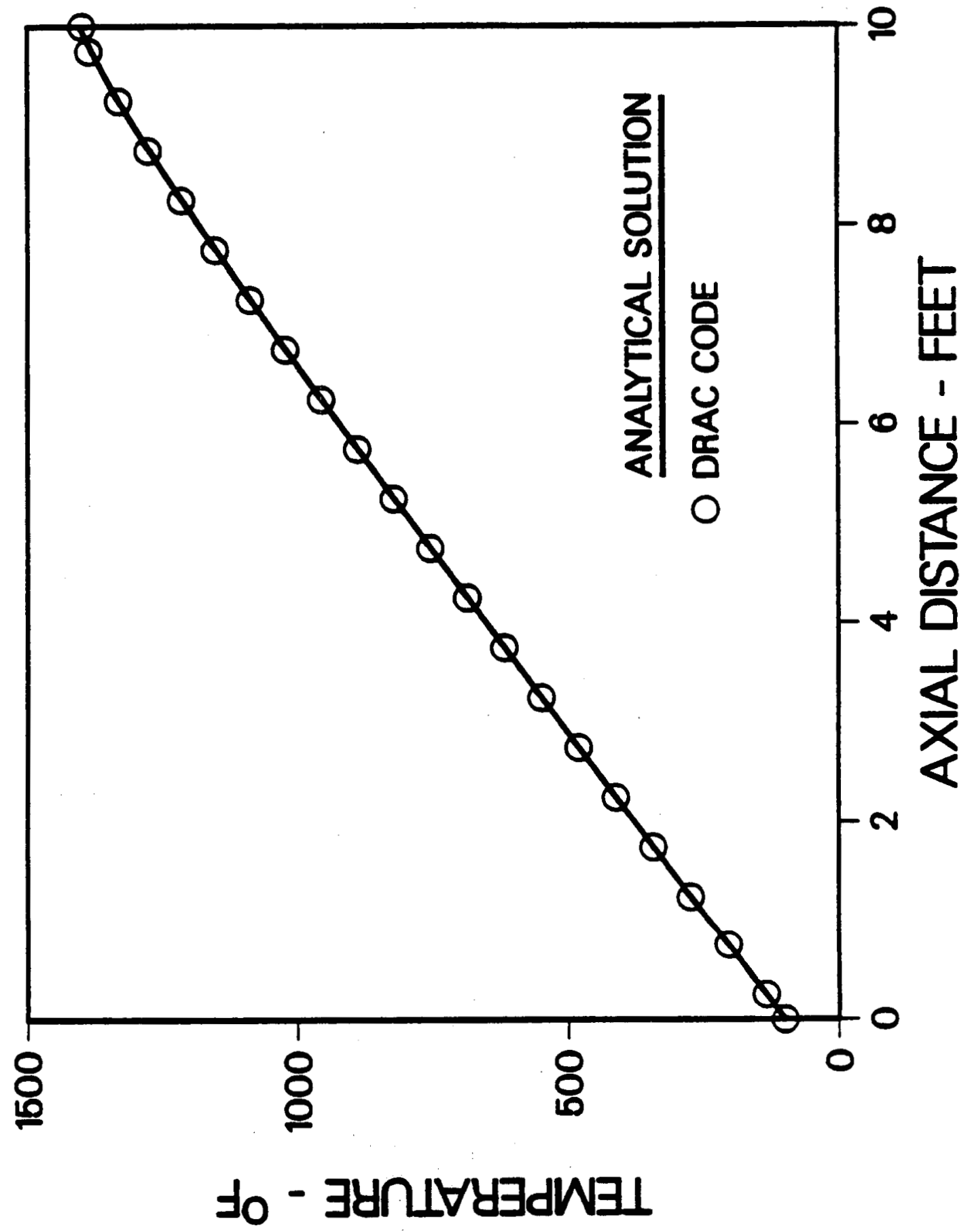

Figure 15.

Comparison of DRAC and Analytical Solution for Axial Fluid Temperature Distribution: Air Test Case. 


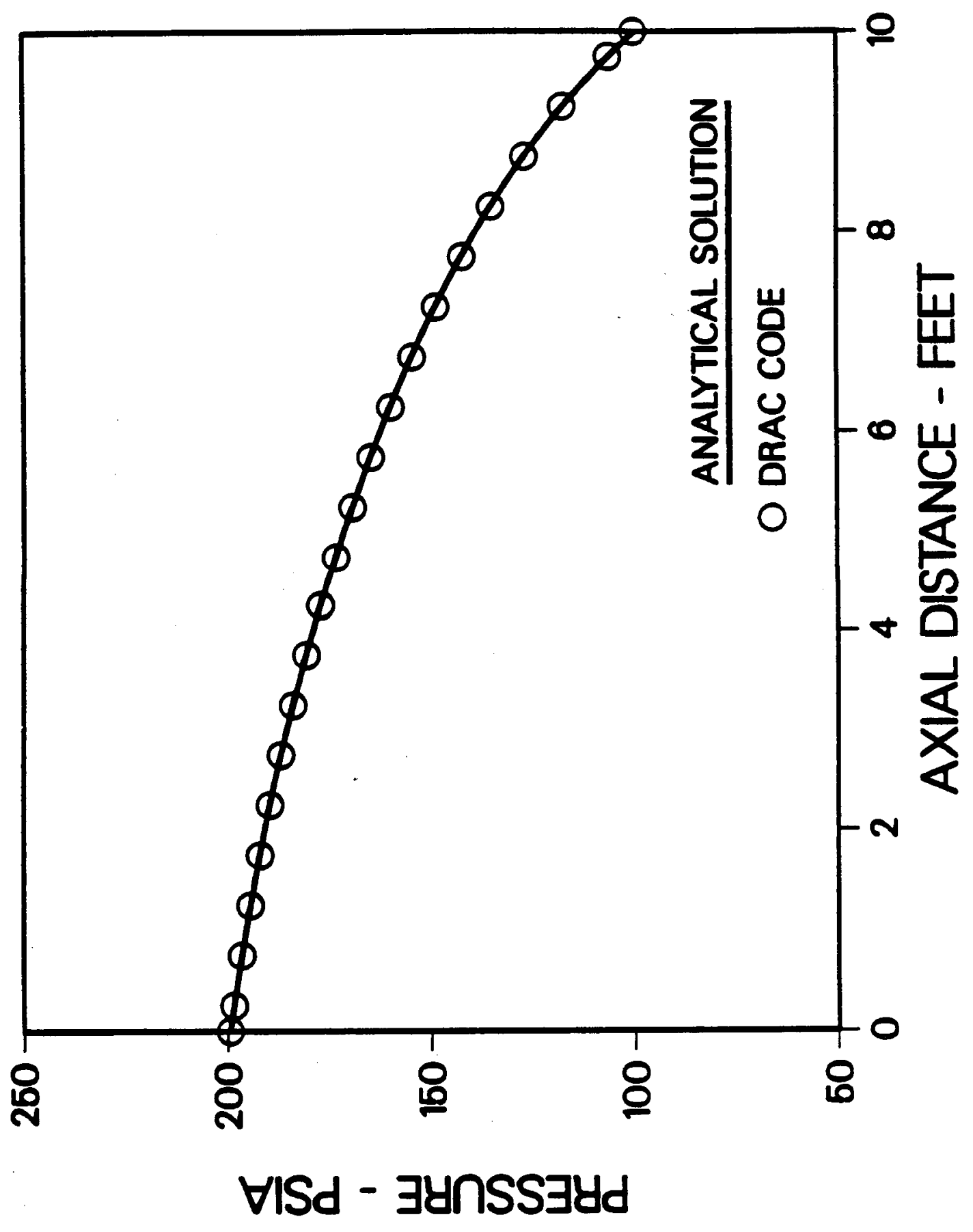

Figure 16.

Comparison of DRAC and Analytical Solution for Axial Fluid Pressure Distribution: Air Test Case 


\section{DRAC User Instructions}

\section{A. Requirements for Input}

DRAC is currently operational on the Sandia Livermore Cray Computer. Users may exercise the code by submitting prepared lists of Cray sy stem commands either through Intercom or a card deck. Users need not be concerned with preparing the list of Cray commands, but the user must supply a file (disk, tape, or cards) containing the namelist input data.

For the most economical application of the code, the user is urged to take advantage of dynamic dimensioning in the code. The amount of memory allocated during computations will be a minimum if the user specifies $N_{c v}, N_{R}$, and $N_{c}$ in the parameter statement of the main DRAC program. This can be done through the Intercom Editor.

All user input data is made available to DRAC through a single namelist called INPUT. The constants which make up this list are defined as follows where the type of the variable is indicated in parentheses:

IID - Receiver tube inside diameter in feet (real).

OD - Receiver tube outside diameter in feet (real).

ZLONG - Total length of receiver tube in feet (real).

THETA - Receiver tube orientation, angle from horizontal in degrees (real).

FMIN - Minimum allowable tube wall friction factor, unitless (real).

MATS - Flag identifying tube wall material type (integer).

$1=$ Stainless steel 18-8

$2=$ Incoloy 800

MATL - Flag identifying fluid type (integer).

$1=$ Ideal gas air, constant $C_{\text {po }}$

$2=$ Molten draw salt, $60 / 40$ wt pet

3 = Liquid sodium

4 = Ideal gas air, variable $C_{\text {po }}$

HAMB - Coefficient of convective heat transfer to the ambient in $\mathrm{Btu} / \mathrm{s}-\mathrm{ft}^{2}-{ }^{\circ} \mathrm{F}$ (real).

TAMB - Ambient temperature in ${ }^{\circ} \mathrm{F}$ (real).

TINLET - Inlet fluid temperature in ${ }^{\circ} \mathrm{F}$ (real).

POTLET - Outlet fluid pressure in psia (real). 
RINLET - Estimated inlet fluid density $\mathrm{lbm} / \mathrm{ft}^{3}$ (real).

ALPHA - Unitless solar absorptivity (real).

EPS - Unitless tube wall emissivity (real).

NQ

- Number of pairs of points (from 2 to 20 ) required for user specificied normalized axial heat flux profile (real).

Q

- List of 2 to 20 points defining the normalized axial heat flux distribution (real). If less than 20 points are required to describe the heat flux distribution, the remaining points must be assigned an arbitrary numerical value, say zero. For example, the $Q$ values required to describe the distribution in Figure 6 would be $Q=.1,1, ., 1,17 * 0$. This entry corresponds to $\mathrm{NQ}=3$.

ZQ - List of 2 to 20 points defining the axial location in feet corresponding to the above $Q$ values (real). For the heat flux distribution in Figure 6 , the $\mathrm{ZQ}$ entries would be given by $\mathrm{ZQ}=0 ., 5 ., 10,17 * 0$. This entry corresponds to $N Q=3$.

NQP - Number of pairs of points (from 2 to 20) required for the user to describe how the peak heat flux, $Q_{p}$, changes with time (integer).

QP - List of 2 to 20 points defining the peak heat flux in Btu/s-ft ${ }^{2}$ as a function of real time (real). Rules for $Q_{p}$ entries are identical to the rules for $Q$ entries.

TMQP - List of 2 to 20 points defining the real time coordinates in seconds corresponding the above QP values (real). Rules for TMQP entries are identical to the rules for $\mathrm{ZQ}$ entries.

NW - Number of pairs of points (from 2 to 20) required for the user to describe how the inlet mass flow rate changes with time (integer).

W - List of 2 to 20 points defining the inlet mass flow rate in $\mathrm{lbm} / \mathrm{s}$ as a function of real time (real). Rules for $\mathrm{W}$ entries are identical to the rules for $Q$ entries.

TMW - List of 2 to 20 points defining the real time coordinates in seconds corresponding to the above $W$ values (real). Rules for TMW entries are identical to the rules for $\mathrm{ZQ}$ entries.

IEDIT - A five element array (integer) defining which dependent variables will be printed out during minor edits. The five interger entries correspond to the numbers assigned to computational nodes by the mesh generator.

TMAX - Real time in seconds at which computations will be terminated (real).

DTMINR - Real time increment in seconds between minor edits (real). For example, if DTMINR $=.1$, the values of five dependent variables 
defined by the IEDIT entry will be printed out every $1 / 10$ of a second NDTMAJ - An integer variable which defines the frequency of major edits. If $\mathrm{NDTMAJ}=10$, then the values of all dependent variables in the model will be printed out every $10 \times$ DTMINR real time seconds.

The user must take care to insure that no infinite gradients (i.e., step functions) appear in the description of the normalized axial heat flux (arrays $Q$ and $Z Q$ ), the time-dependent peak heat flux (arrays QP and TMQP), or the time-dependent inlet mass flow rate (arrays $W$ and TMW). Doing so is likely to cause the numerical integration routines in DASSL to return an error, thus bringing a halt to calculations. Step changes in these input values may be approached by using extremely steep ramps.

The use of DRAC can most effectively be demonstrated through the sample problem discussed in the following section.

\section{B. Sample Problem}

It is desired to examine the transient response of an Incoloy 800 sodium cooled receiver subjected to repeated, alternating $100 \%$ step changes in mass flow rate and repeated, alternating $50 \%$ step changes incident heat flux. The receiver tubing is 10 feet long with a smooth inner surface (FMIN =0.) having an ID of .0543 feet. The tube has an $O D$ of .0625 feet and is oriented vertically. An axially uniform heat flux having a peak value of $116.22 \mathrm{Btu} / \mathrm{s}-\mathrm{ft}^{2}$ is applied to the tube under nominal conditions. The nominal mass flow rate is $W=.5 \mathrm{lbm} / \mathrm{s}$. The remaining conditions for this test case are:

$\begin{array}{ll}\text { Ambient heat transfer coefficient } & =5.55 \times 10^{-4} \mathrm{Btu} / \mathrm{s}^{-\mathrm{ft}^{2}} \\ \text { Ambient temperature } & =70^{\circ} \mathrm{F} \\ \text { Inlet sodium temperature } & =550^{\circ} \mathrm{F} \\ \text { Exit sodium pressure } & =45.98 \mathrm{psi} \\ \text { Estimated inlet density at } 550^{\circ} \mathrm{F} & =55.1 \mathrm{lbm} / \mathrm{ft}^{3} \\ \text { Tube absorptivity } & =.9 \\ \text { Tube emissivity } & =.9\end{array}$


In this example 20 fluid control volumes will be used along with the minimum number of tube wall heat conduction nodes, i.e., $N_{c v}=20, N_{R}=3$, and $N_{c}=3$. These values must be set by using the Intercom Editor to alter a single parameter statement in the DRAC main program.

The namelist data file for this example is given in Table II. Examination of the array $Q P$ vs. TMQP, and W vs. TMW indicates that in the interval $0 \preceq t \prec 50$ the receiver is operating at nominal peak heat flux and flow rate. Actually this is the period of time allocated for the start-up transient. At $t=50$ seconds the receiver will be operating at its steady-state nominal condition. From 50 seconds on, disturbances may be summarized as follows:

\begin{tabular}{|c|c|c|c|c|c|}
\hline 0 & $\preceq$ & $t$ & $\prec$ & 50 & $\begin{array}{l}\text { Time used for code to achieve nominal flow steady-state } \\
\text { starting conditions }\end{array}$ \\
\hline 50 & $\preceq$ & $t$ & $\prec$ & 51 & Steep ramp increase in mass flow from .5 to 1.0 \\
\hline 51 & $\preceq$ & $t$ & $\prec$ & 100 & Maintain $W=1.0$ \\
\hline 100 & $\preceq$ & $t$ & $\prec$ & 101 & $\begin{array}{l}\text { Steep ramp decrease in mass flow from } 1.0 \text { to } .5 \\
\text { (return to nominal conditions) }\end{array}$ \\
\hline 101 & $\preceq$ & $t$ & $\prec$ & 150 & Maintain nominal $\mathrm{W}$ and $\mathrm{QP}$ \\
\hline 150 & $\leq$ & $t$ & $\prec$ & 151 & Steep ramp decrease in peak heat flux from 116.2 to 58. \\
\hline 151 & $\preceq$ & $t$ & $\prec$ & 200 & Maintain QP $=58.1$ \\
\hline 200 & $\preceq$ & $t$ & $\prec$ & 201 & $\begin{array}{l}\text { Steep ramp increase in peak heat flux from } 58.1 \text { to } 116.2 \\
\text { (return to nominal conditions) }\end{array}$ \\
\hline & & 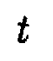 & $\prec$ & 250 & Maintain nominal $\mathrm{W}$ and $\mathrm{QP}$ \\
\hline
\end{tabular}

The peak outer tube wall temperature and receiver exiting fluid temperature which result from the above disturbances are plotted vs. time in Figure 17. The responses to near step changes in mass flow rate and peak heat flux are clearly visible in the plot. Temperature changes during the startup transient ( $0 \preceq t \prec 50)$ are also shown. These plotted temperature histories were generated from transcribing and plotting printed values from minor edits. The minor edits were printouts of nodal variables at nodes $1,2,3,236$, and 245 (see values for IEDIT in Table II) which occured for every second of real time (DTMIMR = 1.). If the user consults the mesh generation table in Appendix B (generated by DRAC prior to calculations) and the printout of major and minor edits in Appendix C, it quickly becomes apparent that nodal values $1,2,3,236$, and 245 correspond to inlet pressure, inlet temperature, inlet mass flow rate, outer crown temperature near the exit, and exit fluid temperature respectively. 
TABLE II.

NAMELIST INPUT FOR SAMPLE PROBLEM

$\$$ INPUT

$\mathrm{ID}=.05433$,

$\mathrm{OD}=.06250$,

$\mathrm{ZLONG}=10$.,

THETA $=90$.,

$\mathrm{FMIN}=0$.,

MATS $=2$,

$\mathrm{MATL}=3$,

$\mathrm{HAMB}=5.555555 \mathrm{E}-4$,

$\mathrm{TAMB}=70$,

TINLET $=550$.

POTLET $=45.98$,

RINLET $=55.1$

$\mathrm{ALPHA}=.9$,

$\mathrm{EPS}=.9$,

$\mathrm{NQ}=3$,

$\mathrm{Q}=1 ., \quad 1 ., \quad 1 ., \quad 17^{*} 0$.

$\mathrm{ZQ}=0 ., \quad 5 ., \quad 10 ., \quad 17^{*} 0$.,

$\mathrm{NQP}=6$,

$\mathrm{QP}=116.22, \quad 116.22, \quad 58.11, \quad 58.11, \quad 116.22, \quad 116.22, \quad 14^{*} 0$,

TMQP $=0$., 150., 151., 200., 201., 1000., 14*0.,

$\mathrm{NW}=6$,

$\mathrm{W}=.5, \quad .5, \quad 1 ., \quad 1 ., \quad .5, \quad .5, \quad 14^{*} 0$.,

TMW=0., 50., 51., 100., 101., 1000., $14 * 0$.,

$\mathrm{IEDIT}=1, \quad 2, \quad 3,236, \quad 245$,

$\mathrm{TMAX}=250$,

$\mathrm{DTMINR}=1$,

$\mathrm{NDTMAJ}=10$,

$\$$ END 


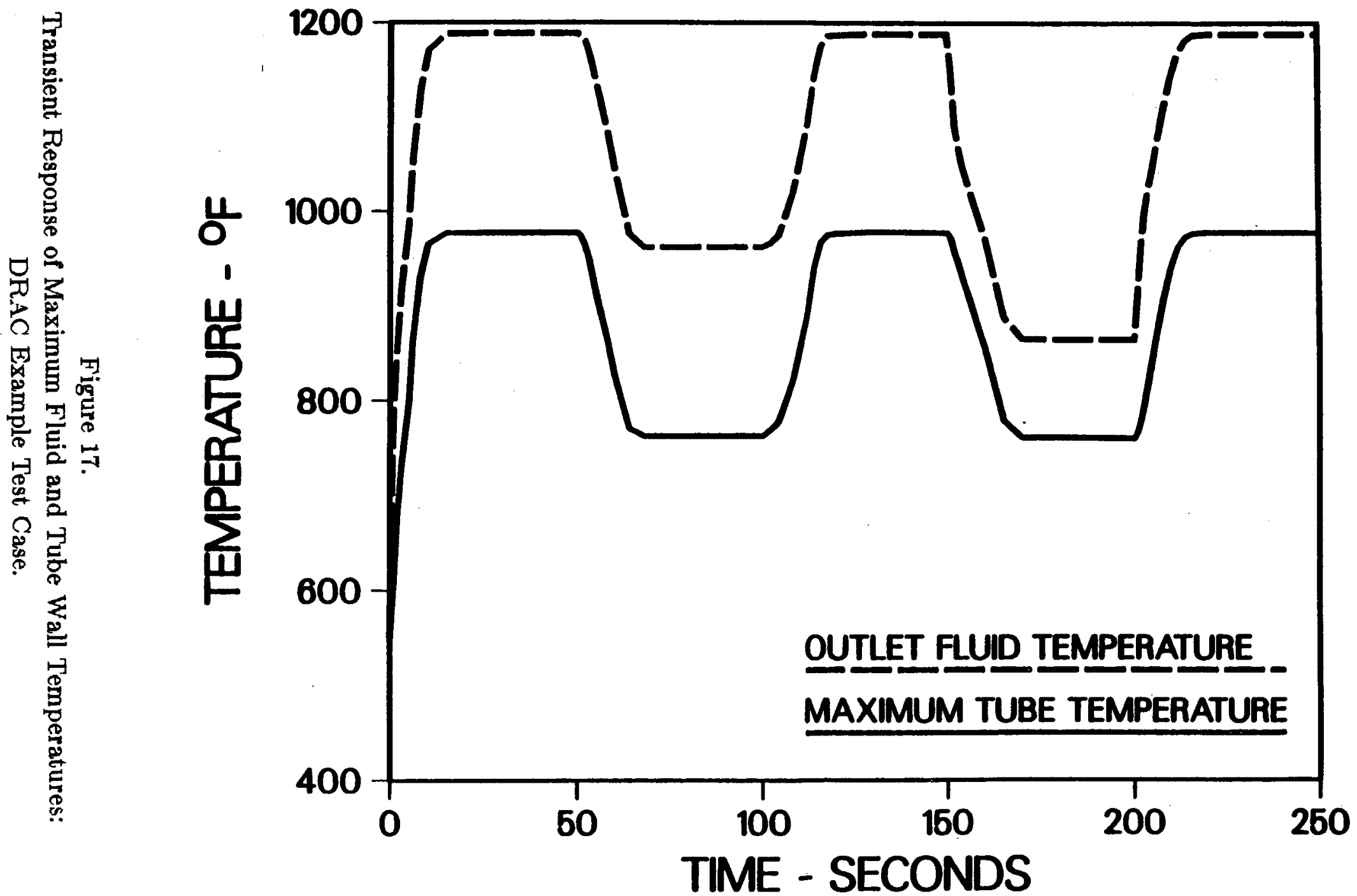


For large problems (many nodes) it may be difflcult for the user to select which minor edit variables to print vs. time without first examining the Mesh Generation Table. Hence the user may wish to make a brief calculation say over the interval $0 \preceq t \preceq .001$ solely for the purpose of examining the DRAC mesh for his problem. For this short calculation the user may arbitrarily assign IEDIT values of $1,2,3,4$, and 5. After examination of the Mesh Generation Table the user can quickly determine locations of any pressure, mass flow, and temperature within the computational mesh and redefine the IEDIT values to suit his needs. The relationship and location of variables in the mesh remains unaltered so long as the values $N_{c v}, N_{R}$, and $N_{c}$ are not changed.

In addition to the Mesh Generation Table and the printout of major and minor edits, DRAC also produces a header with additional information. Included with this header is the description of units and a list of the users namelist input. For this example, the header information is given in Appendix A. 


\section{Conclusions/Future Activities}

It has been shown that highly generalized computer programs TOPAZ and DASSL can be combined into user oriented codes for solving more specific classes of problems. The first of these user friendly codes, DRAC, models transient flows through receiver tubing. DRAC accepts a concise set of namelist input data, generates a computational mesh, and directs the DASSL numerical integration of TOPAZ hydrodynamic and heat conduction equations. Virtually all of the "tedium" associated with manipulating data arrays, providing steady-state starting conditions, and printing out the results has been made transparent to the user.

The accuracy of the DRAC code has been demonstrated for steady-incompressible and compressible flows. Results from DRAC calculations compare favorably with independent numerical calculations, as well as analytical solutions. Validation of DRAC transient calculations can be demonstrated in the future, if an appropriate independent analysis or calculation for transient receiver flow becomes available.

Future activities in this area will be restricted to providing documentation for TOPAZ and writing additional versions of DRAC, as required. Additional user friendly codes for modeling other solar oriented heat transfer/fluid flow situations (i.e. heat exchangers, plant flow loops, etc.) can also be written as new applications arise. 


\section{References}

1. V. H. Ransom, R.J. Wagner, et al., "RELAP5/MOD1 Code Manual Volume 1: System Models and Numerical Methods", NUREG/CR-1826, EG\&G Idaho, Inc., Idaho Falls, Idaho 83415, March 1981.

2. R. V. Moore, et al., "RETRAN - A Program For One-Dimensional Transient Thermal-Hydraulic Analysis of Complex Fluid Flow Systems, Volume 1: Equations and Numerics", EPRI NP-408, Energy Incorporated, P. O. Box 736, Idaho Falls, Idaho 83401, January 1977.

3. L. N. Kmetyk, and R. K. Byers, "Analysis of 70-Tube Pilot Plant Solar Receiver Panel Test Data", SAND81-1220, Sandia National Laboratories, Albuquerque, NM, August 1981.

4. L. N. Kmetyk and R. K. Byers, "Analysis of Five-Tube Solar Receiver Panel Test Data", SAND81-0402, Sandia National Laboratories, Albuquerque, NM, April 1981.

5. L. Petzold, "A Description of DASSL: A Differential/Algebraic System Solver", to be published in The Proceedings of the IMACS World Congress, Montreal, Canada, August 1982.

6. W. S. Winters, "Dynamic Modeling of Solar Central Receivers", SAND818213, Sandia National Laboratories, Livermore, CA, July 1981. 
. 


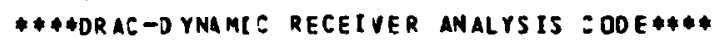

DIRECT QUESTIONS TII BILL WINTERS, EXTENSION 2367

JNITS FOR INPJT AND DUTPUT SHOULO BE CONSISTENT WI TH THE FOLLOUIVG

LENGTHS = FEET

$\triangle N G L$ ES = - - DEGREES

IEMPERATURE EDEG F

PRESSURE = PSI

TIME- SEC

DENSITY= LBMICU FT

HTCE
HEAT FLUX= BTUISEC-SO FT

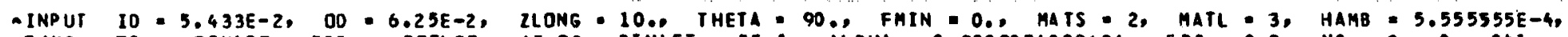

POTLET 45.98, RINLET = 55.1, ALPHA $=0.9339374399604$, EPS = 0.9, NO 31 $0.3 * 1.017 * 0.0$

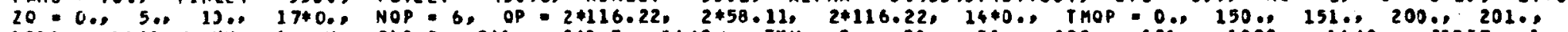

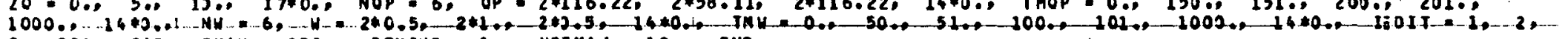

3. 236,245, TMAX $=250.9$ DIMINR $=1 .$, NDTMAJ $=10$, AEND 
APPE.VDIX B.

DRAC Abbreviated Printout of Mesh Generator Table

MESH GENERATION TABLE FOLLOHS:

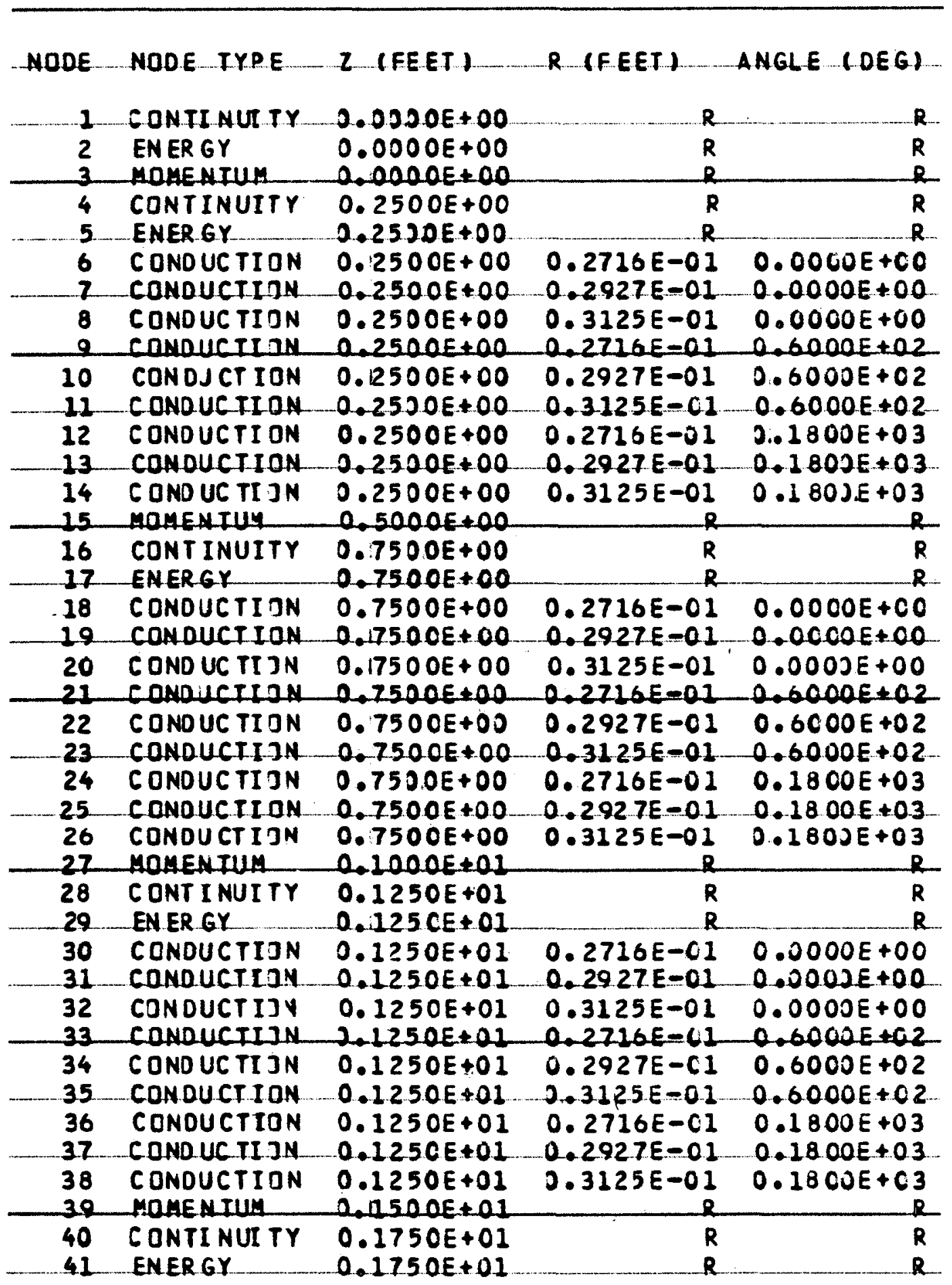




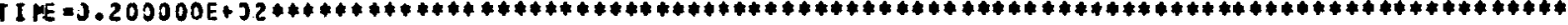
PI $11=0.50035 E+02$ II $21=0.54991 E+03$ KI $31=0.5000 J E+00$ PI $41=0.49934 E+02$ II $51=0.56061 E+03$ If 6$)=0.62969 E+03$ II $71=0.70611 E+03$ TI $81=0.77347 E+03$ TI $91=0.59579 E+03$ T( $101=0.63453 E+03$ T( $111=0.6603 T E+03$ TI $121=0.560 \mathrm{BLE}+33$ T( 13$)=0.56099 E+03$ TI 14$)=0.5610 \mathrm{BE}+03$ WI $151=0.50000 \mathrm{E}+00$ $P(1.6)=0.49725 E+02$. T( 17$)=0.53203 E+03 \ldots T(18)=0.65150 E+03-T(19)=0.72786 E+03-T(20)=0.79517 E+03$ TI $211=0.61739 E+03$ TI $221=0.65608 E+03$ TI 23$)=0.68989 E+03$ TI $241=0.58223 E+03$ TI $251=0.58241 E+03$ II $261=0.58250 E+C 3$ VI $271=0.50000 E+00$ P( $281=0.49517 E+02$ TI $291=0.60349 E+03$ II $301=0.67335 E+03$ II $311=0.74964 E+03$ II 32$)=0.81689 E+03$ TI 33$)=0.63904 E+03$ II 34$)=0.67767 E+03$ T( 35$)=0.71143 E+03$ T( 36$)=0.6 C 369 E+C 3$ TI 37$)=0.60387 E+03$ TI 38$)=0.60396 E+03$ HI 39$)=0.500(0 E+03$ P( $401=0.49309 E+02$ TI $411=0.62497 E+03$ TI $421=0.69523 E+03$ II $431=0.77145 E+03$ II $441=0.83864 E+03$ TI $451=0.66071 E+03$

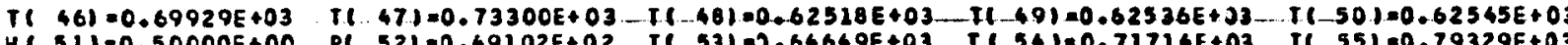
$H(51)=0.50000 E+00$ PI $521=0.49102 E+02$ TI $531=0.64649 E+03$ TI $541=0.71724 E+03$ TI $551=0.79329 E+03$ I $561=0.06041 \equiv+03$ TI $571=0.68241 E+03$ TI 58$)=0.72094 E+03$. TI $591=0.75460 E+53$ (I $6(6)=0.64670 E+03$

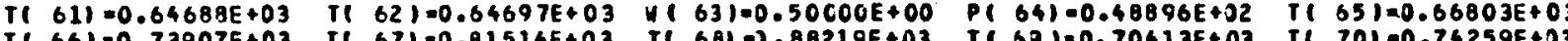
$T(66)=0.73907 E+03$ T 671 (I) TI $71=0.77620 E+03$ Tf $721.0 .66024 E 003$ T I (

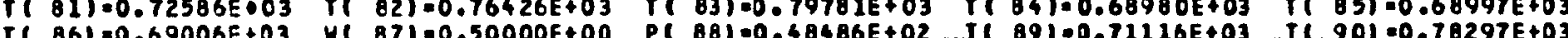
TI

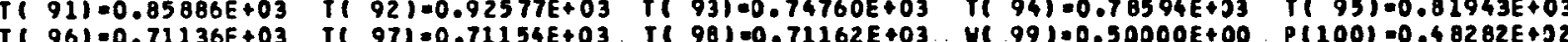
$T(101)=0.73273 E+3 \quad T(102)=0.80493 E+03 \quad T(103)=0.88073 E+03 \quad T(104)=0.94756 E+03 \quad T(105)=0.76933 E+03$ T(306)

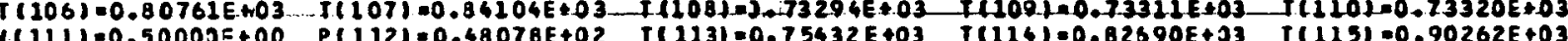

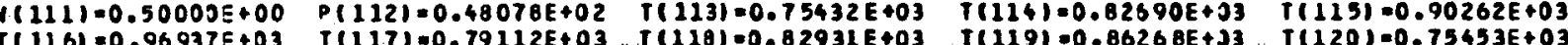

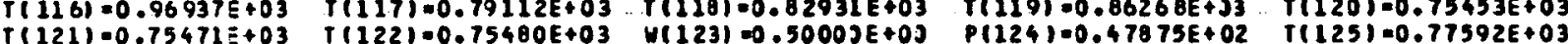

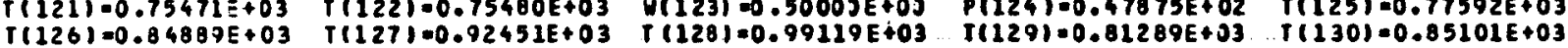

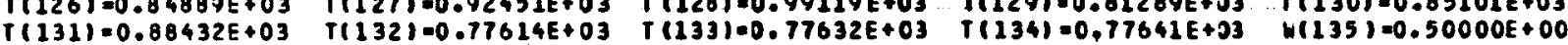

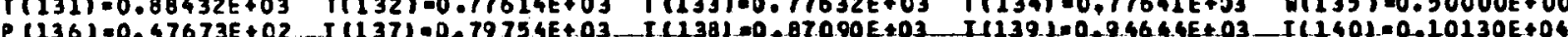
$T(141)=0.83470 E+03 \quad T(142)=0.87275 E+03 \quad T(143)=0.90599 E+03 \quad T(144)=0.797 T 8 E+33 \quad T(145)=0.79798 E+03$

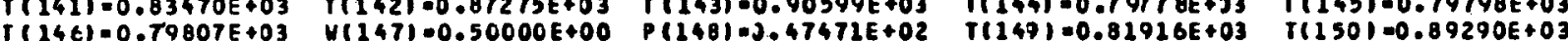
T(151)=0.96835E-03 T(152)=0.10349E+04 T(153)=0.85648E+03 T(154)=0.89447E+03 T(155)=0.92764E+03 $T(156)=0.81941 E+03 \quad T(157)=0.01961 E+03$ T $(158)=0.81971 E+03 \quad N(159)=0.50000 E+2) \quad P(160)=0.47271 E+02$ (161)-0.84084E+03 T(162)-C.91496E+03 T(163)-0.99029E+03 T(164)=0.10567E+04 T(165)=0.87832E+03 $T(166)=0.91622 E+03 \quad T(167)=0.94932 E+03-T(168)=0+84109 E+03-T(1669)$ $(171)=0.50000 E+00$ P(172) $=0.47070 E+02 \quad T(173)=0.06238 E+03 \quad T(174)=0.93685 E+03 \quad T(175)=0.10121 E+04$ $T(176)=0.10794 E+04 \quad T(177)=0.90000 E+03 \quad T(278)=0.93 T 80 E+J 3 . T(177)=0.97082 E+03 . T(180)=0.86262 E+03$ $1(181)=0.8628 \mathrm{~L} E+03 \quad T(182)=0.06290 E+03 \quad V(183)=0.50 C 00 E+00 \quad P(184)=0.46871 E+02 \quad T(185)=0.88413 E+03$ $T(190)=0.95956 E+03$ (191)-0.99243E+03 T(192)-0.88434E+03 T(193)=0.80451E+03 T(194)=0.88459E+03 $\quad$ (195)=0.50000E+00 $P(196)=0.46672 E+02 \ldots T(197)=0.0$ $T(201)=0.94317 E+03 \quad T(2 C 2)=0.90073 E+03 \quad T(203)=3.10136 E+04 T(204)=0.90549 E+03 \quad T(2) 5)=0.90563 E+03$ $T(206)=0.90570 E+03 \quad V(207)=0.50000 E+00 \quad P(2 C \theta)=0.46473 E+02 \quad T(209)=0.92743 E+03 \quad T(210)=0.10029 E+04$ $T(211)=0.10777 E+04 \quad T(212)=0.11436 E+04 \quad T(213)=0.96540 E+03 \quad T(214)=0.10028 E+04 \quad T(215)=0.10356 E+04$ $T(216)=0.92758 E+03 \quad T(217)=0.92770 E+03 \quad T(218)=0.02777 E+03 \quad W(219)=0.50000 E+00 \quad P(220)=0.46275 E+02$ $T(221)=0.94749 E+03 \quad T(222)=0.10232 E+04 \quad T(223)=0.10979 E+04 \quad T(224)=0.11637 E+04 \quad T(225)=0.98556 E+03$ $T(226)=0.10229 E+06 \quad T(227)=0.10555 E+J 4-T(228)=0.04762 E+02 \quad T(229)=0.94773 E+03 \quad T(230)=0.94779 E \cdot 03$ $\forall(231)=0.50000 E+00 \quad P(232)=0.4607 \theta E+02 \quad T(233)=0.97151 E+03 \quad T(234)=0.10477 E+04 \quad T(233)=0.11222 E+04$ $T(236)=0.12879 E+04 \quad T(237)=0.10098 E+04 \quad T(238)=0.10470 E+04 \quad T(239)=0.10796 E+04 \quad T(240)=0.97168 E+03$ $T(241)=0.97182 E+03 \quad T(242)=0.97190 E+03 \quad V(243)=0.50001 E+00$ P(244)=0.45980E+02 T(245)=0.97686E+03

I IME $=0.210000 E+02$ TIHE $=0.220000 E+02$ TI TIME $-0.240000 \mathrm{~T}+02$ TIME TIME TIME $0.0200000 E+02$ TIME $=0.2900000 \times 02$ TI ME $=0.300000 \mathrm{E}+02$

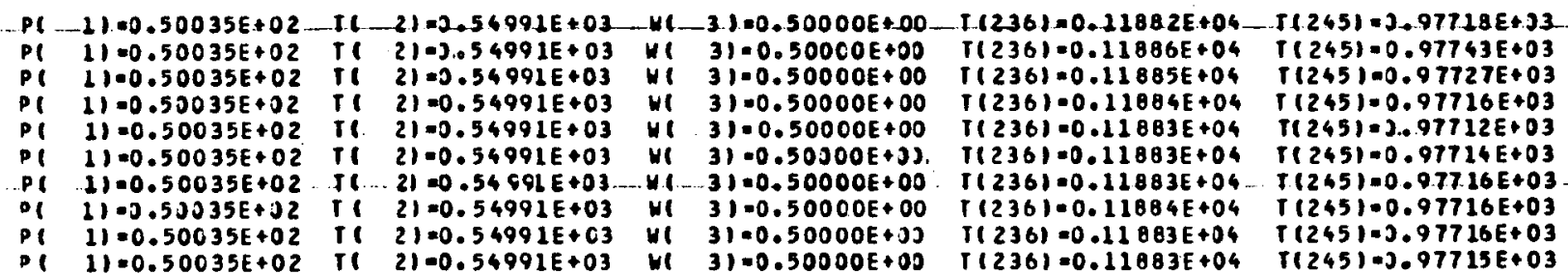


$\therefore \quad$ i 
UNLIMITED RELEASE

INITIAL DISTRIBUTION:

U. S. Department of Energy

Attn: G.W. Braun

K. Cherian

C. McFarland

James Forrestal Building

1000 Independence Avenue, S.W.

Washington, D.C. 20585

U. S. Department of Energy

San Francisco Operations Office

Attn: R. W. Hughey, C. Mangold

1333 Broadway

Oakland, CA 94612

U. S. Department of Energy

Albuquerque Operations Office

Attn: J. Morley

P. O. Box 5400

Albuquerque, NM 87115

Solar Energy Research Institute

Attn: B. L. Butler

B. Gupta

G.Gross

J. Thornton

R. Edelstein

1536 Cole Boulevard

Golden, CO 80401

C. Winter, 400

A. Narath, 10

T. B. Cook, 20 
D. W. Larson, 1513

S. L. Thomson, 9444

R. K. Byers, 9444

L. Kmetyk, 9444

E. H. Beckner, 9700

D. G. Schueler, 9720

W. P. Schimmel, 9721

J. V. Otts, 9722

J. A. Leonard, 9727

J. F. Banas, 9728

R. S. Claassen; Attn: A. N. Blackwell, 8200

B. F. Murphey, 8300

L. Gutierrez, 8400

D. L. Hartley, 8500

D. M. Olson, 8100; Attn: R. C. Wayne, 8110

J. D. Gilson, 8130

J. L. Wirth, 8150

D. E. Gregson, 8160

L. D. Bertholf, 8120; Attn: G. A. Benedetti, 8121

C. S. Hoyle, 8122

W. D. Zinke, 8123

R. J. Gallagher, 8124

M. J. Fish, 8125

C. T. Yokomizo, 8132

R. L. Rinne, 8320; Attn: J. Vitko, 8328

G. W. Anderson, 8330

R. J. Kee, 8331

L. R. Petzold, 8331

P. J. Eicker, 8431

A. C. Skinrood, 8452

P. Delaquil, 8453

W. C. Peila, 8453

C. L. Yang, 8453

W. G. Wilson, 8453 (8)

W. S. Winters, Jr., 8125 (10)

Publications Division, 8265 
Publications Division, 8265, for TIC (27)

Technical Library Processes Division, 3141 (3)

M. A. Pound, 8214, for Central Technical Files (3) 


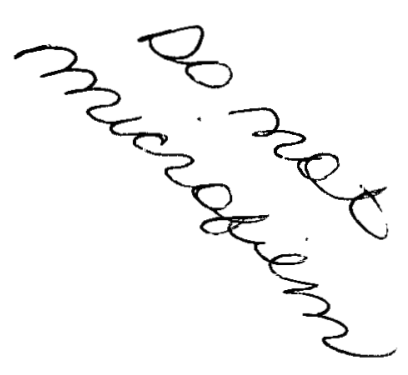

. 